\title{
CONSOLIDAÇÃO DO PROCESSO DE PLANEJAMENTO DO SETOR ELÉTRICO BRASILEIRO (1960-1994)
}

Luziene Dantas de Macedo ${ }^{1}$

RESUMO: O Ponto de partida deste trabalho é apresentar uma discussão sobre a formação e estruturação do moderno Setor Elétrico Brasileiro (SEB), considerando aspectos constitutivos do planejamento específico do SEB, ocorridos a partir de 1960. Pretende-se, assim, como objetivo geral, realizar uma breve análise do SEB, considerando alguns aspectos relevantes da estruturação do setor e a experiência de planejamento setorial do Estado a partir da expansão do sistema elétrico em bases fundamentadas tanto no planejamento integrado como no grau de desenvolvimento econômico do país representado por um capitalismo industrial avançado.

Palavras-Chave: Setor Elétrico Brasileiro; Estado; Planejamento Setorial.

ABSTRACT: The starting point of this paper is to present a discussion about the formation and structuring of the modern Brazilian Electric Sector (SEB), considering constitutive aspects of the specific planning of the SEB, which began in 1960. It is intended, as a general objective, to carry out A brief analysis of the SEB, considering some relevant aspects of the sector's structuring and the State's sector planning experience from the expansion of the electricity system on the basis of both integrated planning and the degree of economic development of the country represented by advanced industrial capitalism.

Keywords: Brazilian Electricity Sector; State; Sector Planning.

1 Doutora em Economia e professora do Departamento de Economia da UFRN. E-mail: luzienedm@uol.com.br. 


\section{INTRODUÇÃO}

As décadas de 1960 e 1970 do século XX marcaram para a economia brasileira, no que tange a experiência de planejamento do Estado, um período de consolidação e auge das atividades de planejamento econômico. Isso é fruto da orientação advinda da política de industrialização adotada no país desde suas primeiras iniciativas de planejamento econômico nas décadas de 30 e 40 do referido século ${ }^{2}$, passando pelo Plano de Metas do governo Kubitschek.

Conseguindo, assim, a partir de 1964 e, com maior veemência nos anos de 1970, não somente preservar as linhas gerais da política de industrialização adotadas nas décadas anteriores, mas também utilizar a capacidade técnica acumulada para aprofundar o planejamento governamental nesse período (REZENDE, 2009; ALMEIDA, 2006).

Claro que essas experiências acabaram significando um avanço no processo de implementação do planejamento setorial, configurando-se, no período, o processo de formulação de planos regionais para o setor de energia elétrica, bem como, sua estruturação a partir de uma visão de longo prazo e na ideia de que os projetos alternativos devem ser comparados conforme seu potencial de contribuir para a geração de energia ao menor custo possível (LEITE, 2007).

Trata-se de um período importante para o Setor Elétrico Brasileiro (SEB), porque os projetos de investimento buscaram definir a fonte de geração mais apropriada e, com isso, o sentido da intervenção do Estado no referido setor. Isso ocorre dentro de uma discussão que foi iniciada no período anterior, mas que ganhou a partir da década de 1960 um viés de desenvolvimento capaz de atender a lógica de acumulação de capital que se estabeleceu no país.

Ora, as décadas de 1960 e 1970 corresponderam, no plano da industrialização mais avançado, uma evolução do capital produtivo e da montagem de um departamento produtor de bens de produção. Claramente, o setor de energia elétrica

\footnotetext{
${ }^{2}$ Conselho Federal de Comércio Exterior, criado ainda nos anos 30, Plano Quinquenal de Obras e Reaparelhamento da Defesa Nacional (1942), Plano de Obras (1943), Missão Cooke, 1942-1943, Missão Abbink, 1948, Comissão Mista Brasil- Estados Unidos (1951-1953), Plano Salte, durante o Governo de Eurico Gaspar Dutra (1946-50), etc. (REZENDE, 2009; ALMEIDA, 2006).
} 
vai sendo sincronizado nessa teia de decisões estratégicas para o país, levando consigo o desenvolvimento do próprio setor de produção de material elétrico avançado.

Optou-se, assim, realizar uma breve análise do SEB, a partir de 1960 até meados da década de 1990, considerado um período relevante para o país, em geral no que tange a implantação das indústrias de base, de consumo duráveis e de bens capital, até o final da década de 1970, bem como em termos da definição do tipo de geração de eletricidade no país. Para tanto, fez-se necessário realizar tanto uma revisão bibliográfica como uma coleta de informações em trabalhos e análises já publicadas na forma de livros e periódicos.

\section{ESTRUTURAÇÃO DO SEB}

Como parte da estruturação do setor, a criação do Ministério das Minas e Energia (MME), considerado como sendo a "órbita específica da administração federal encarregada de todos os estudos e despachos dos assuntos relacionados à energia $\mathrm{e}$ produção mineral" (CACHAPUZ, 2002, p. 20), da Eletrobrás ${ }^{3}$, em 1962 ${ }^{4}$, como empresa holding ancorada incialmente em quatro subsidiárias (Furnas Chesf, Eletrosul e Eletronorte), estando também cercada por empresas estaduais (distribuidoras e geradoras), e mesmo por algumas empresas privadas de menor porte, da consolidação de empresas regionais - Furnas e Chesf - e da maturidade alcançada pela Centrais Elétricas de Minas Gerais S. A. (CEMIG), significaram passos importantes rumo a implementação de um planejamento integrado para o setor (DIAS, 1988), tendo a Eletrobrás assumido, dentre outras funções, a de elaborar e coordenar o planejamento do setor, a partir da década de 60 .

Isso posto, entende-se que existia a convicção de que a intervenção do Estado era necessária para que o que setor elétrico pudesse expandir sua oferta, razão porque se encaminhou, a partir desse período, várias iniciativas importantes para a efetiva coordenação e organização do setor, muitas das quais já tramitavam no Congresso há

\footnotetext{
${ }^{3}$ A estrutura organizacional da Eletrobrás é integrada por três diretorias - Diretoria Jurídica, Diretoria Econômico-Financeira e Diretoria Técnica (DIAS, 1988).

${ }^{4}$ Constituída por quatro companhias: Furnas, Chesf, Companhia Hidrelétrica do Vale do Paraíba (CHEVAP) e a Termoelétrica de Charqueadas (TERMOCHAR) (PINTO, Jr., 2007).
} 
muito tempo, como a constituição da Eletrobrás, cujo projeto fora pensado sete anos antes (LEITE, 2007).

Sob o regime militar, instaurado em 1964, ocorreram várias reformas dentro do SEB, a saber: o MME sofreu modificações que incluíram a reestruturação de órgãos da administração direta responsáveis pelas funções normativas, de fiscalização e controle dos serviços de eletricidade; a Eletrobrás reformulou, em 1964, seu Estatuto, reorganizando sua estrutura de modo descentralizado e, em 1967, 1968, 1976 e 1979 foram realizadas novas modificações na administração da Eletrobrás; em 1965, fora promulgado a Lei 4.904, que transformou a antiga Divisão de Águas do Departamento Nacional de Produção Mineral (DNPM) no Departamento Nacional de Águas e Energia (DNAE), sendo mais tarde denominado de Departamento Nacional de Águas e Energia Elétrica (DNAEE).

Com isso, estava montada a estrutura básica da administração dos serviços de eletricidade: de um lado tinha-se o "DNAEE, órgão normativo e fiscalizador do setor [...], e de outro a Eletrobrás, empresa responsável pelo planejamento e execução da política federal de energia elétrica" [grifos nossos] (CACHAPUZ, 2002, p. 24).

Desse modo, o moderno setor elétrico do país apresentava um arcabouço político-institucional que imprimia uma ordenação dinâmica a partir do desenvolvimento das relações, não mais entre o poder público e o setor privado, mas entre a órbita do Estado e da empresa pública (LIMA, 1995). Isso porque desde Furnas, propriamente dito, que visava atender o Sudeste e parte do Centro-Oeste, até a criação do MME e do período pós-64, quando a Eletrobrás adquire o caráter de agência eminentemente planejadora setorial e holding de empresas federais, o Estado adquiriu, no conjunto desse setor, papel preponderante tanto no processo de implementação de um planejamento setorial integrado, como na condução de projetos ambiciosos de expansão do setor elétrico do país, sustentados pela visão de uma maior participação das empresas públicas.

De modo que, até a década de 1970, o SEB conseguiu assegurar a configuração em tela, estruturando as atividades com um objetivo muito claro, o de permitir um grau de sustentabilidade maior nos serviços prestados, principalmente porque tinha-se, 
também, avançado no financiamento dos investimentos, contando, para tanto, com o autofinanciamento, financiamento interno e financiamento externo (PINTO Jr., 2007) ${ }^{5}$.

Reestruturando, assim, um modelo de desenvolvimento do setor no país capaz de assegurar o pleno abastecimento de eletricidade com capacidade crescente de expansão dos sistemas elétricos, por meio da integração regional e de um conjunto de iniciativas que vão desde a expansão de geração até a construção de linhas de transmissão.

\section{O SENTIDO DO PLANEJAMENTO SETORIAL: O PAPEL DO CANAMBRA}

Um passo importante no sentido de uma configuração mais racional do processo de planejamento em curso, sob a organização político-institucional do Estado, foi a realização de trabalhos relativos ao Sudeste (antes chamada de Região Centro-Sul), organizados sob a sigla de Canambra ${ }^{6}$, no início da década de 1960; e a criação, em 1963, do Comitê Coordenador de Estudos Energéticos da Região Sudeste ${ }^{7}$.

No que se refere aos trabalhos de Canambra, desenvolvidos no âmbito do Comitê em tela, pode-se considerar que este constituiu "o maior e mais completo planejamento elétrico integrado até então realizado no mundo ocidental" (DIAS, 1988, p. 208).

Seu primeiro relatório fora concluído em 1963, o que fez com que a ideia de planejamento passasse de uma análise individualizada de projetos para a ideia de inventário dos projetos possíveis ${ }^{8}$, "cujos custos eram comparados aos de uma usina térmica a óleo combustível, de capacidade equivalente" (LEITE, 2007, p. 288). Além do que fora realizado uma série de diagnósticos do setor, de modo a se ter todas as

\footnotetext{
${ }^{5} \mathrm{O}$ autofinanciamento consiste na reinversão dos recursos das próprias empresas para os investimentos de expansão do setor. O financiamento interno se dava através dos recursos advindo de diversos impostos e empréstimos compulsórios, sendo o Imposto Único de Energia Elétrica (IUEE) o tipo de financiamento mais importantes desta estrutura; já o financiamento externo diz respeito a participação de bancos internacionais e de organismos multilaterais de crédito, muitos dos quais acabaram ditando os rumos pelo qual o processo de planejamento deveria perpassar (PINTO Jr., 2007).

${ }^{6}$ Que corresponde ao consórcio formado pela Montreal Engineering Co, G. E. Crippen and Associates, canadenses, e Gibbs and Hill, norte-americana (LEITE, 2007). A designação Canambra deve-se a reunião de três países envolvidos: Canadá, estados Unidos e Brasil (DIAS, 1988).

${ }^{7}$ Que reunia Furnas (Eletrobrás), e os estados da Guanabara, Minas Gerais, São Paulo e Rio de Janeiro (PINTO Jr., 2007).

${ }^{8}$ À época o inventário do potencial hidráulico estimado foi de $38.000 \mathrm{MW}$.
} 
informações possíveis e relevantes quanto as necessidades prementes naqueles pontos considerados fatores de estrangulamentos à expansão do sistema elétrico do país.

Com isso, detectou-se os seguintes pontos que demandavam ações efetivas do Estado para o completo desenvolvimento do setor, segue um resumo desses pontos destacados por Pinto Jr., (2007, p. 211) e Leite (2007, p. 288-289):

- A distância cada vez maior entre os centos de produção e os centros de consumo, fazendo com que se tivesse de um lado a geração e do outro a distribuição;

- A necessidade de um planejamento integrado das bacias hidrográficas, sinalizando a importância de se pensar a interligação dos sistemas elétricos entre as principais empresas da região Sudeste. Logo, "justificava-se o planejamento integrado de longo prazo" (LEITE, 2007, p. 289)

- A necessidade unificação da frequência que situava entre $50 \mathrm{~Hz}$, no Rio de Janeiro, Rio Grande do Sul e Espírito Santo, e $60 \mathrm{~Hz}$, nas demais regiões. Pela Lei 4.454, de 06 de novembro de 1964, no seu Art. 1ํㅡㄹ fica adotada a frequência de 60 Hertz para distribuição de energia elétrica no território nacional (LEI 4.454, de 06 de novembro de 1964) ${ }^{10}$;

- A necessidade de elaboração de estudos de mercado mais completos e que pudessem resolver o problema de suprimento de energia até a década de 1970, por meio de medidas prioritárias.

De acordo com o referido autor, o primeiro relatório de Canambra, referente a Região Sudeste, foi aprovado em 1964, pelo Decreto ㄲo 53.958 (LEITE, 2007), recomendando um programa de investimentos do setor elétrico até 1966, para atender a demanda prevista até 1970 (DIAS, 1988).

Contudo, fora incumbido à Eletrobrás, em 1964, a tarefa de acompanhar a execução dos projetos propostos pelo Canambra, gerando, em 1967, a aprovação de

\footnotetext{
${ }^{9}$ A partir da inauguração de Furnas, em 1965, integraram-se fisicamente São Paulo, Rio de Janeiro e Belo Horizonte, bem como a partir da incorporação da usina termelétrica de Santa Cruz, em 1967, mostrou a Furnas a possibilidade de se pensar em uma operação hidrotérmica (LEITE, 2007).

${ }^{10}$ A unificação de frequência, coordenada pela Eletrobrás, havia sido sugerido pela Comissão para Unificação de Frequência (CUF), instituída pelo Conselho Nacional de Águas e Energia Elétrica (CNAEE), em 1961 (MEMÓRIA DA ELETRICIDADE, 2013).
} 
um relatório final com estudos direcionados à região Sudeste ${ }^{11}$ (ECCARD, 2012). A partir daí "o governo federal delegou à Eletrobrás, além da coordenação dos investimentos propostos, a alternativa da eventual revisão do programa de desenvolvimento da região" (ECCARD, 2012, p. 20).

A realização da revisão, com a inclusão nos estudos do potencial hidro e térmico da região Sul, bem como, de seu referido mercado, gerou outro relatório final e mais completo, que foi aprovado em 1970, por meio do Decreto no $66.737^{12}$ (LEITE, 2007). Sendo assim, "as conclusões obtidas foram incorporadas à sistemática de planejamento adotada pelo programa de Ação Econômica do Governo (PAEG) (1964-1966) e pelo Programa Estratégico de Desenvolvimento (PED) (1968-1970)" (DIAS, 1988).

A partir de Canambra foram organizados informalmente grupos permanentes de estudo e planejamento, primeiro em Furnas e depois no âmbito da diretoria de Planejamento e Engenharia da Eletrobrás, separando-se as funções de planejamento, de engenharia e operação ${ }^{13}$ (LEITE, 2007).

Com isso, o planejamento baseava-se numa forma determinada de decisão para o referido setor, tendo ele a capacidade de retratar a situação econômica do país e as necessidades que haveriam de ser demandadas ao SEB para tornar possível o crescimento econômico do país.

No final da década de 1960, o referido setor já tinha avançado substancialmente no seu processo de implantação de planejamento mais integrado, tendo a Eletrobrás participado das principais decisões referentes ao desenvolvimento do SEB e dos estudos referentes ao inventário das bacias hidrográficas, estando, assim, consolidado seu papel nas etapas de planejamento de expansão do e de transmissão de longa distância e conexões inter-regionais (CACHAPUZ, 2002).

Desde logo, foram formuladas várias medidas direcionadas para colocar em prática os planos de expansão de geração de energia elétrica, cujas decisões viriam encadear uma série de projetos de desenvolvimento para o país, e a eletricidade, como

\footnotetext{
${ }^{11}$ Nesse segundo relatório foram apresentadas diretrizes para um programa de investimentos de longo prazo, estudos adicionais de mercado e o inventário de um potencial estimado em $38.000 \mathrm{MW}$ (DIAS, 1988).

${ }_{12}^{12}$ Levantou-se um potencial estimado em 10.000 MW (DIAS, 1988).

${ }^{13}$ No que diz respeito a operação, Leite (2007) assinala que essa função ficou a cargo do Comitê de Coordenação da Operação Interligada (CCOI), que atuavam na Região Sudeste desde 1969 e na Região Sul, desde 1971.
} 
insumo básico desse processo, precisava ser encarada, à essa altura, não como um setor isolado do resto da atividades políticas, econômicas e sociais, mas como um setor sincronizado, pois as decisões tomadas nesse campo alimentariam os projetos em curso e/ou vias de projeção.

Isso posto, constata-se que a própria Eletrobrás passou a "estruturar atividades de caráter contínuo ou periódico, capazes de alimentar e dar continuidade às decisões" (DIAS, 1988, p. 209).

Nesse contexto, em 1967 dá-se início a um programa de estruturação de obras e os estudos de mercado, criando, em 1968, o Orçamento Plurianual de Energia (OPE), considerado um importante instrumento de planejamento, o qual passou a resumir para um período de oito anos - três passados e cinco projetados - os investimentos setoriais realizados e projetados (CACHAPUZ, 2002).

O referido documento destacou análises de dados e de projeção de investimentos, os quais sinalizaram a capacidade de expansão do setor e, com isso, ele não se torna apenas um instrumento orçamentário, mas um amplo documento, que reúne todo um arcabouço analítico do setor, configurando-se num instrumento importante para a tomada de decisões passíveis de serem efetivadas à luz do que já havia sido realizado, podendo, a partir daí, dar um passo à frente nos projetos de expansão do setor em tela.

O OPE evoluiu posteriormente para o Programa Plurianual de Investimentos do Setor Elétrico (PPE), "que atualmente integra um documento anual mais abrangente, 0 Programa de Recuperação do Setor Elétrico (PRS)” (DIAS, 1988, p. 210).

\section{NOVOS ESTUDOS REALIADOS: EVOLUÇÃO DAS ATIVIDADES DE PLANEJAMENTO SETORIAL}

Em 1968 é realizado um estudo pela Eletrobrás ${ }^{14}$. Conhecido pelo título da versão em inglês - Power Market Study and Forecast - South Central Brazil (PMS \& F), tal estudo buscava revisar algumas projeções realizadas pelo Canambra no tocante ao suprimento de energia elétrica.

${ }^{14} \mathrm{O}$ Banco Mundial solicitou um estudo que revisasse as projeções realizadas pelo Canambra, com o objetivo de subsidiar as negociações de novas linhas de financiamento para obras de geração (ECCARD, 2012, p. 20). 
Logo, foram realizadas projeções relativas ao suprimento para os estados de Minas Gerais, Espírito Santo, Rio de Janeiro, Guanabara, São Paulo e áreas adjacentes pertencentes ao Distrito Federal, sul de Goiás e o sudeste do Mato Grosso, sendo o ano de 1985 considerado a base das projeções (CACHAPUZ, 2002).

As diferenças, em relação aos trabalhos pioneiros do Canambra, foram a inclusão da totalidade dos estados de Minas Gerais e do Espírito Santo e a exclusão do norte do Paraná, por outro lado, seguiram a metodologia adotada no Canambra, que englobou o crescimento do Produto Interno Bruto (PIB), o crescimento da população, a taxa de urbanização e a questão tarifária.

No tocante ao estudo sobre o mercado de energia elétrica, o PMS \& F realizou algumas alterações metodológicas em relação àquela considerada pelo Canambra. Contribuindo, assim, para o estabelecimento de um estudo de mercado mais voltado a realidade do SEB e dos projetos de desenvolvimento em curso ou em vias de se realizar.

O referido estudo permitiu que a Eletrobrás implantasse "um esquema de acompanhamento da evolução do mercado das principais concessionárias do país, visando detectar as diferenças entre as projeções e o consumo verificado" (CACHAPUZ, 2002, p. 58).

Posteriormente, este estudo foi revisado novamente sob o título Revisão do Balanço Energético (1972-1985) - RBE-72 -, concluído em 1972 (LEITE, 2007). A ideia aqui era incluir nas projeções de suprimento de energia elétrica para a região Sudeste, tanto o crescimento substancial da economia brasileira advindo do período conhecido como "Milagre Econômico (1968-1973), como os objetivos que estavam sendo planejados para a economia brasileira, quando o I Plano Nacional de Desenvolvimento (I PND - 1972-1974) "já anunciava os programas de expansão da siderurgia, petroquímica, construção naval, corredores de transportes, energia elétrica, comunicações e mineração, detalhados mais tarde pelo II PND, no governo Geisel" (LIMA, 1995, p. 97).

Em relação à estimativa realizada pelo PMS \& $\mathrm{F}$, que considerou taxas médias de crescimento anual do consumo de energia elétrica regional entre $9,5 \%$ e 10,7\%, no período 1968-1975, o RBE-72 considerou essa projeção; diferentemente aconteceu no 
tocante a expansão do sistema elétrico da região Sudeste até $1980^{15}$, visto que este conferiu maior ênfase ao desenvolvimento da hidroeletricidade de grande porte ${ }^{16}$ (CACHAPUZ, 2002). Segundo autor citado

[...], a nova programação era equivalente à da Canambra [...]. Seus 14 projetos assegurariam a capacidade instalada de $20.901 \mathrm{MW}$ E 10.86 MW de capacidade firme em dezembro de 1980 , enquanto o programa de Canambra, com 23 projetos, previra $21.486 \mathrm{MW}$ de capacidade instalada e $10.300 \mathrm{MW}$ de capacidade firme (CACHAPUZ, 2002, p.112).

Na extensão dos estudos até 1985, considerou-se o aproveitamento hidroelétrico de Itaipu, que até então não havia sido estimada a potência final de geração, apenas projeções de capacidade de geração, no qual situou-se em $8.000 \mathrm{MW}^{17}$ até o ano citado.

A economia brasileira começou a experimentar, desde 1968, taxas de crescimento substancial do produto, sendo este liderado pelo crescimento das atividades do setor público e da indústria de bens de consumo duráveis. Este momento exigiu, notadamente no SEB, previsões de suprimento de eletricidade capazes de dar conta das políticas de desenvolvimento econômico a ser implantadas na década de 1970, porque já era opinião geral nesse momento, no mundo e no Brasil, que o acesso à eletricidade é condição essencial para o desenvolvimento de um país (PINTO Jr., 2007).

Nesse contexto, a Eletrobrás tinha a preocupação de realizar planejamentos setoriais condizentes com as exigências desse período, que era o de tornar realizáveis os objetivos destacados no I PND e II PND (1975-1979), fazendo com que a expansão da Oferta Interna da Energia Elétrica (OIEE) pudesse responder às projeções crescentes da demanda de eletricidade, já que a liderança desses planos seria

\footnotetext{
${ }^{15}$ Pelo estudo do PMS \& F, focou estimado, para 1980 um acréscimo na geração de 1,3\% para energia e de $11,1 \%$ para ponta, comparando-se com as projeções realizadas pelo projeto da Canambra, o que equivale 10.262 MW médios para energia e 19.816 MW para ponta (CACHAPUZ, 2002, p. 56).

${ }_{16}$ Sendo inclusive recomendado a expansão de capacidade instalada de alguns projetos hidrelétricos estudos pela Canambra, tais com Jupiá, Estreito e llha Solteira, ao passo que outros foram excluídos (lbid., 2002).

${ }^{17}$ No final do projeto de construção de Itaipu fora estimado uma capacidade de geração de $12.600 \mathrm{MW}$, compreendendo 18 unidades geradoras de $700 \mathrm{~kW}$ (DIAS, 1988).
} 
comandada, respectivamente, pelos setores de bens duráveis de consumo e de bens de produção. Em relação a este último setor, sua expansão

[...] impunha acentuada expansão da oferta de energia, não apenas em função do ritmo de crescimento econômico previsto, mas porque tratava-se de setores cujo padrão tecnológico estava associado a elevado consumo energético, especialmente a produção de insumos básicos (LIMA, 1995, p.114).

Neste ambiente de crescimento econômico e de implantação de vários projetos de desenvolvimento, quando o grupo Eletrobrás começa a experimentar um período de crescimento com a criação de novas empresas controladas ${ }^{18}$, ampliando, de um lado, sua presença nos investimentos e na produção e, de outro, requerendo a transferência de recursos das empresas do setor (LIMA, 1995), o planejamento setorial passa por um processo de evolução e de discussão importantes a partir da decisão de construir a Usina Hidrelétrica de Itaipu, em 1973.

Este fato consegue imprimir um passo importante na institucionalidade do SEB no qual se desenha, pela Lei 5.899/1973 e Decreto Legislativo n 114-A do mesmo ano, uma concepção de usina hidrelétrica com significativa extensão da construção da usina, tal como foi a de Furnas, constituindo-se, portanto, o último marco da organização do SEB nesse período, comandado pela intervenção estatal na geração de eletricidade e operação de seus serviços de modo centralizado e efetivamente planejado para suportar períodos longos de estiagem.

Nas palavras de Leite (2007), dada sua escala de 12.600 MW, a Itaipu Binacional significava "a oportunidade histórica de se completar o longo percurso de organização do setor elétrico brasileiro" (LEITE, 2007, p. 154), bem como nasce aqui a ideia tanto de operação interligada como o de operação hidrotérmica, o que vai exigir "novos rumos do planejamento da expansão e da operação dos sistemas elétricos das regiões Sudeste e Sul" (CACHAPUZ, 2002, p. 74), bem como a obrigatoriedade, pela Lei de Itaipu $^{19}$, das empresas, que operam na área servida por Itaipu, planejar sua expansão

${ }^{18}$ Em 1968 foi constituída a Centrais Elétricas do Sul da Brasil (Eletrosul), como subsidiária da Eletrobrás, que teve seu funcionamento autorizado em 1969, no mesmo ano em que fora autorizado a continuidade da obra da usina de Passo Fundo, no estado do Rio Grande do Sul (LIMA, 1995). Em 1972, a Eletrobrás avançou novamente com a criação da Centrais Elétricas do Norte do Brasil (Eletronorte).

${ }^{19}$ A concepção da Lei de Itaipu pode ser resumida conforme se segue: confirmar à Eletrobrás as funções de coordenação técnica, financeira e administrativa, e de orientação geral do programa de expansão dos 
considerando a absorção de toda a energia proveniente da referida usina (CACHAPUZ, 2002; LIMA, 1995).

Destaca-se também, não sendo menos importante, a ideia da construção da usina de Tucuruí, no sudoeste do Pará ${ }^{20}$. Com capacidade projetada para gerar 7.000 MW, sendo $3.960 \mathrm{MW}$ na primeira etapa e $3.300 \mathrm{MW}$ na segunda etapa, é considerada a maior usina hidrelétrica inteiramente brasileira, bem como vale mencionar a importância do seu sistema de transmissão, que, em 1981, já beneficiava parte do estado do Pará, pela interligação com a Chesf (DIAS, 1988).

No campo do grupo da Eletrobrás, a ideia da construção de Itaipu significou a consolidação da holding federal, que, também, por esse período, passava por um processo de reorganização do seu grupo ${ }^{21}$ (LIMA, 1995), o que exigiu a constituição, em 1973, do Grupo de Coordenação da Operação Interligada (GCOI) ${ }^{22}$, que substituía o CCOI. Segundo Goldenberg \& Prado (2003), o GCOI ${ }^{23}$ realizava o planejamento do sistema operacional para um horizonte de cinco anos, objetivando

serviços de energia elétrica; reter para o $\operatorname{DNAEE}^{19},[\ldots]$, a concessão de instalações, a fiscalização técnica e financeira dos serviços concedidos e a aprovação de tarifas; e, finalmente, descentralizar a atividade executiva, de produção, transmissão e distribuição de energia elétrica, tendo em vista a diversidade e a dimensão geográfica do país; Definia-se com precisão o âmbito de atuação das quatro subsidiarias regionais da Eletrobrás. (LEITE, 2007, p. 154).

${ }^{20}$ Suas obras foram concluídas em 1984.

21 Art. $2^{\circ}$ da Lei 5.899 , de 05 de julho de 1973 destaca que são consideradas subsidiárias da ELETROBRÁS de âmbito regional: I - Centrais Elétricas do Sul do Brasil S. A. - ELETROSUL, com atuação nos Estados do Rio Grande do Sul, Santa Catarina e Paraná; II - FURNAS - Centrais Elétricas S. A., com atuação no Distrito Federal e nos Estados de São Paulo, Minas Gerais, Rio de Janeiro, Guanabara, Espírito Santo, Goiás e Mato Grosso, estes dois últimos, respectivamente, ao Sul dos paralelos de 15 30' (quinze graus e trinta minutos) e 18(dezoito graus); III - Companhia Hidro Elétrica do São Francisco - CHESF, com atuação nos Estados da Bahia, Sergipe, Alagoas, Pernambuco, Paraíba, Rio Grande do Norte, Ceará, Piauí e Maranhão; IV - Centrais Elétricas do Norte do Brasil S. A. ELETRONORTE, com atuação nos Estados de Goiás, Mato Grosso, respectivamente, ao norte dos paralelos de $15^{\circ} 30^{\prime}$ (quinze graus e trinta minutos) e $18^{\circ}$ (dezoito graus), Pará, Amazonas e Acre e Territórios Federais de Rondônia, Roraima e Amapá.

${ }_{22}$ Composto por representantes do DNAEE, Eletrobrás e das empresas geradoras e distribuidoras da região (LIMA, 1995).

${ }^{23} \mathrm{Em} 1968$ foi instituído o Eneram, que é o Comitê Coordenador dos Estudos Energéticos da Amazônia, com o que foram realizados estudos energéticos da Amazônia, entre 1969 e 1971, nos moldes como estava sendo realizados para as regiões Sul e Sudeste, o que contribuiu para entender que era possível o aproveitamento dos rios das Amazônia para efeito de geração de energia elétrica, desde que fossem construídos os empreendimentos após uma distância média de 250 quilômetros de cada margem do Amazonas; em 1969 fora criado o Comitê Coordenador dos Estudos Energéticos do Nordeste, conhecido como Comitê Nordeste, ou simplesmente Enenorde, que realizou estudos energéticos para aquela região entre 1970 e 1972 sendo apresentado o relatório final em 1973 com a recomendação e três obras de geração no sistema Chesf, Paulo Afonso IV, Xingó e o reservatório de Sobradinho, dentre outras recomendações (CACHAPUZ, 2002). 
Em primeiro lugar, garantir a continuidade do suprimento de energia elétrica aos sistemas distribuidores, [...]; em segundo lugar, promover a economia de combustíveis utilizados nas centrais termoelétricas, restringindo seu consumo ao mínimo indispensável à complementação do sistema predominantemente hidráulico (DIAS, 1988, p.211).

$\mathrm{Na}$ década de $1970^{24}$, a expansão dos sistemas interligados permitiu o melhor aproveitamento da capacidade instalada das empresas geradoras de eletricidade, da diversidade hidrológica, da "melhor qualidade do serviço, por meio de menores variações da frequência ${ }^{25}$, maior controle dos níveis de tensão e auxílio em emergências" ${ }^{\prime 6}$ (DIAS, 1988, p. 212), bem como a referida década significou a extrapolação do processo de planejamento da ótica regional, característico da década de 1960, no qual, por meio da realização de planos de expansão para as regiões Sul e Sudeste (Plano 1990, a ser abordado em seguida), foram estudados pela primeira vez dois sistemas interligados de uma forma global, bem como destaca-se a incorporação de estudos sobre a indústria de equipamentos e materiais elétricos ${ }^{27}$.

\subsection{O PLANO 90}

Dias (1988) assinala que a partir da década de 1970 foram previstos uma série de crise de suprimento de energia elétrica na região Sudeste, já por volta de 1990:

Em virtude do esgotamento dos recursos hidrelétricos locais, naquela ocisão subestimados, bem como da suposta inviabilidade de transmissão a longa distância para o aproveitamento do potencial hidrelétrico da bacia amazônica, e,

\footnotetext{
${ }^{24}$ Nessa década, a ação planejadora da Eletrobrás enfrentou dificuldades, em virtude das duas crises do petróleo e da elevada elevação dos custos financeiros, de modo que o planejamento a médio e longo prazos foi praticamente abandonado, em função da necessidade de resolver a gestão financeira dos recursos (DIAS, 1988)

${ }^{25}$ Isso significava que com a interligação do sistema elétrico, a partir de Itaipu, haveria maior controle e dimensionamento das frequências, podendo acompanhar sua carga de modo mais efetivo, pois as menores variações significavam ao mesmo tempo uma forma otimização do sistema e qualidade do serviço ofertado.

${ }^{26}$ A operação interligada permitiu que os reservatórios, situados em diferentes bacias hidrográficas, que não têm nenhuma ligação física entre si, funcionem como se fossem vasos comunicantes. Ou seja, "se chove pouco na bacia do rio São Francisco e muito na bacia do rio Paraná, a usina de Paulo Afonso é orientada a colocar pouca energia na rede [...], e a usina de Itaipu faz a compensação. Ao colocar mais potência na rede, Itaipu cede água, indiretamente, para Paulo Afonso (BENJAMIN, 2001, p. 10).

${ }^{27} \mathrm{Na}$ tentativa de integrar os diversos agentes do setor elétrico (indústrias de equipamento, empresas de construção civil, firmas de engenharia) (DIAS, 1988).
} 
ainda, da própria velocidade do crescimento do consumo de energia elétrica ${ }^{28}$ (DIAS, 1988, p. 212).

Tais problemáticas pressionaram o país para que se tomassem algumas medidas efetivas à expansão da capacidade instalada de eletricidade, antecipando os projetos que envolvesse a opção da geração termelétrica, no caso a energia nuclear ${ }^{29}$, bem como de decisões para a construção de usinas hidroelétricas de grande porte, notadamente Itaipu e Tucuruí.

Além do mais, como a construção de Itaipu determinaria novos rumos no planejamento do setor, como já enfatizado, a Eletrobrás começou a elaborar planos de expansão do sistema de atendimento dos serviços de energia elétrica ${ }^{30}$ para as regiões Sul e Sudeste, em atendimento a Lei de Itaipu: o primeiro foi concluído em 1973, chamado de Revisão do Balanço Energético 1973-1981 (RBE-73) e o segundo, em 1974, que compreendia também a região Centro-Oeste. Este último ficou conhecimento como o Plano 90 e diz respeito a um horizonte de médio prazo ${ }^{31}$ (CACHAPUZ, 2002; LIMA, 1995, DIAS, 1988).

O RBE-73, que encerra o ciclo de formulação de planos regionais iniciados desde a Canambra, analisou os requisitos de energia elétrica no sistema interligado da região Sudeste e também a capacidade geradora da região Sul, assim como um plano de expansão de transmissão para essas duas regiões, considerando o período 19741981.

O ambiente de realização do referido estudo tinha como base a nova situação internacional, marcada por dois choques do petróleo (1973 e 1979) e pelo aumento das taxas de juros nos EUA, no qual impôs uma conjuntura desfavorável ao aumento dos

\footnotetext{
${ }^{28}$ De fato, no período de 1970 a 1980 , fora acrescentado ao consumo eletricidade $83.037 \mathrm{GWh}$, com taxa de crescimento anual de $12 \%$ (conforme os dados do MME, 2013). Para efeito de comparação, entre 1963 e 1973, foram adicionados ao consumo $34.099 \mathrm{GWh}$, correspondendo uma taxa anual de crescimento de $9,6 \%$.

${ }^{29} \mathrm{O}$ governo planejou um grande programa de construção de reatores nucleares, por meio do Acordo Nuclear Brasil-Alemanha, assinado em 1975 (DIAS, 1988).

${ }^{30}$ Que incluía também uma análise da indústria de equipamentos e materiais, inclusive elétricos, onde as empresas estatais atuariam com o seu poder compra com vistas a desenvolver o setor de bens de capital do país (CACHAPUZ, 2002).

31 Tradicionalmente o setor elétrico realiza o seu planejamento em três horizontes temporais: longo prazo (20 a 30 anos); médio prazo (10 a 15 anos); curto prazo, onde são detalhados os primeiros 10 anos dos programas de obra, definindo-se, para os primeiros 5 anos, os orçamentos plurianuais de investimento e o equacionamento das fontes de recursos financeiros (MME, ELETROBRÁS, 1987).
} 
investimentos, principalmente nos países do terceiro mundo, desencadeando, sobremodo, um processo de dolarização da dívida externa, cujo resultado foi a ocorrência de vários distúrbios financeiros nas contas públicas e a desestabilização tanto da capacidade financeira do Estado como de sua capacidade produtiva.

Tomando-se como referência o estudo de Cachapuz (2002), destaca-se que, em relação ao estudo direcionado para a região Sudeste, o RBE-73 apresentou projeções direcionadas ao consumo de energia elétrica até 1981 , entre $9,5 \%$ e $10,7 \%$, percentuais idênticos aos apresentados em estudos realizados anteriormente ${ }^{32}$.

Referente ao programa de obras, o relatório propôs a instalação de mais de 2.180 MW de potência no período de 1980-1981; para a região Sul, as recomendações foram a de levar em conta os estudos já realizados pelo Canambra, que havia proposto uma adição de mais de 700 MW, até 1981, a partir da "antecipação da entrada em operação da terceira unidade da termelétrica Candiota (CEEE), de duas unidades da termelétrica Jorge Lacerda (ELETROSUL) e pela inclusão da central hidrelétrica Foz do Areia (COPEL)" (CACHAPUZ, 2002, p. 118).

Em relação ao Plano 90, que previa estimativas do intenso crescimento econômico ${ }^{33}$ do país conforme as metas estipuladas no II PND, projetou-se a expansão do SEB até 1979, visando o atendimento das regiões Sul e Sudeste (GONÇALVES Jr., 2002) e ainda de grande parte da região Centro-Oeste, além do que se buscou confirmar a decisão de construção da Usina Hidrelétrica de Itaipu e de outras usinas de mesmo porte, assim como da instalação de oito centrais nucleares, na região Sudeste (CACHAPUZ, 2002).

Do ponto de vista do estudo de mercado, o referido plano previu um crescimento médio do mercado de energia elétrica em torno de $11,7 \%$, até 1979 , nas regiões Sudeste, Centro-Oeste e Sul, estimativa essa verificada em $11,5 \%$, no período 1974 a 1979 (CACHAPUZ, 2002). Por sua vez, considerando o país como um todo, a taxa de crescimento anual do consumo de eletricidade foi de $11,9 \%$ nesse período, quase igual a estimativa apresentada no Plano 90.

\footnotetext{
32 Entre 1974 e 1981 o consumo de energia apresentou uma taxa de crescimento anual de 10,4\%, passando de 63.344 GWh, em 1974, para 126.232 GWh (MME, 2013).

33 O II PND previa um crescimento médio anual do PIB da ordem de 10\%, em 1979. Contudo, o crescimento médio anual do PIB ficou abaixo dessa projeção (6,7\%) (CACHAPUZ, 2002).
} 
Para a década de 1980, as projeções do Plano 90 para o mercado foram de $8,7 \%$ e $11,4 \%$, considerando um crescimento do PIB de, respetivamente, $8 \%$ (dada certa incerteza) e $11 \%$ (considerando o crescimento econômico do período chamado de "milagre brasileiro") (LEITE, 2007; CACHAPUZ, 2002; GONÇALVES Jr., 2002). Mas, em virtude da crise econômico-financeira que assolou o país, e o mundo como um todo, com os dois choques do petróleo e aumento do custo financeira, a taxa de crescimento anual do consumo de eletricidade para o Brasil, durante os anos 1980 a 1990, foi de $5,9 \%$, ou seja, não acompanhou nem a previsão de baixa divulgada no referido plano.

No tocante as estimativas de ampliação do parque gerador, considere a análise realizada por Cachapuz (2002) e Gonçalves Jr. (2002) ${ }^{34}$. Ambos destacaram que as obras previstas se dividiram da seguinte forma: um programa de obras até 1985 (que incluía obras em andamento e a complementação de nove usinas, além de Itaipu e de outras usinas hidrelétricas, termelétricas e nuclear) e três programas alternativos para os anos 1986-1990, prevendo a projeção de alta do mercado (todos previram a construção de usinas nucleares) ${ }^{35}$.

Em adição, constata-se que na projeção baixa de consumo de eletricidade, o acréscimo da capacidade de geração de energia elétrica se situou bem abaixo do cenário de projeção alta de consumo de energia (alternativa I e II). No primeiro cenário, os estudos privilegiaram a construção de novas usinas hidrelétricas, enquanto no outro cenário, a alternativa I, privilegiou-se relativamente a construção de novas hidrelétricas, diferentemente da alternativa II, quando se reduziu a projeção de novos investimentos hidrelétricos em favor do aumento da contribuição das usinas nucleares na capacidade instalada de eletricidade.

\footnotetext{
${ }^{34}$ A base de análise considerava as diversas fontes energéticas disponíveis para comporem o parque gerador das regiões Sudeste, Sul e Centro-Oeste nos 15 anos seguintes. Contava-se à época com aproximadamente 49.000 MW de potencial hidrelétrico, já com Itaipu, distribuídos em 239 locais inventariados nas regiões em tela e desses 72 foram destacados com condições de competir até 1900, além do mais existia a possibilidade de expansão da termoeletricidade e da energia nuclear; nos trabalhos realizados pela Eletrobrás fora constatado um déficit energético superior a $2.000 \mathrm{MW}$ médios em 1982, na região Sudeste, em virtude tanto do aumento do mercado na região, como do atraso das obras de Itaipu (CACHAPUZ, 2002, p. 127 e 129).

${ }^{35}$ Admitindo-se a projeção de baixa de mercado, diminuiria em aproximadamente $10.000 \mathrm{MW}$ médios os requisitos de energia no final da década, não sendo necessário a participação de energia nuclear (Ibid., 2002).
} 


\subsection{O PLANO 95}

No ritmo da tendência de integração dos sistemas elétricos regionais e da nova situação econômico-financeira que o país estava começando a enfrentar, Cachapuz (2002) destacou a necessidade de se implementar o planejamento em escala nacional, e foi aí que se deu início ao primeiro plano com essa orientação elaborado em 1977 com o título Plano Nacional de Atendimento aos Requisitos de Energia Elétrica até 1992.

Já em $1979^{36}$, fora concluído o Plano de Atendimento aos Requisitos de Energia Elétrica até 1995, conhecido como Plano $95^{37}$, que não apenas consolidou, em termos nacionais, os aspectos mais relevantes dos projetos em curso e em estudo (DIAS, 1988), como também marcou a abertura da Eletrobrás em direção a um planejamento efetivamente integrado e de médio prazo ${ }^{38}$ (CACHAPUZ, 2002).

Por tudo isso, o final da década de 1970 traz um dinamismo diferente para a elaboração de um planejamento integrado dessa natureza, porque existe a memória bem nítida das duas crises do petróleo, principalmente da última, em 1979, ano em que foi concluído o Plano 95 - primeiro plano nacional de longo prazo do setor de energia elétrica (CACHAPUZ, 2006).

Certamente, tais fatos vieram contribuir para os novos rumos do SEB, inclusive o de pensar uma política de substituição do petróleo. Com isso, o governo da época pensava em intensificar o uso do carvão na região Sul, ao longo da década de 1980.

Contudo, a Eletrobrás destacou, no referido plano, que o uso mais intenso do carvão deveria ficar condicionado à implementação de uma política de substituição de petróleo (CACHAPUZ, 2002).

\footnotetext{
${ }^{36}$ Antes, em 1978, a Eletrobrás, que realizava os estudos de planejamento de longo, médio e curto prazo, elaborou um estudo de longo prazo denominado Alternativas de expansão da capacidade geradora, com o objetivo de identificar a base do desenvolvimento dos sistemas elétricos brasileiros até 2000 (CACHAPUZ, 2002).

37 Este plano foi o primeiro de uma série de quatro planos nacionais de energia elétrica dentro dos sistemas interligados e isolados elaborados pela Eletrobrás e submetido à aprovação do MME. (CACHAPUZ, 2002).

${ }^{38}$ São estudos que visam a programação de expansão do sistema elétrico do país no prazo de até 15 anos, que, realizados com antecedência, levava-se em conta os longos períodos de construção das usinas geradoras (média de oito anos) e linhas de transmissão (média de cinco anos) (Ibid., 2002).
} 
Claro que também já se cogitava a necessidade de se utilizar outras fontes de energia, mas nada ainda que pudesse ser traçado uma política mais direcionada à quantificação de recursos renováveis existente no país, basicamente em se tratando da biomassa, solar e eólica, nem a programação de planejamento mais voltado à utilização dessas fontes dentro de uma política de substituição do petróleo.

O referido plano atualizou dados referentes ao potencial hidroelétrico nacional, que, "estimado em 104,5 GW médios, permitiam a instalação de uma capacidade de produção de aproximadamente 209 GW" (CACHAPUZ, 2002, p. 134), bem como, adotou previsões menos otimistas para o crescimento do PIB (6\% a 7\% a.a., no período $1979-1995^{39}$ ), em virtude da nova conjuntura mundial agravada pelas duas crises do petróleo.

Segundo o autor supracitado, o Plano 95 não programou nenhuma construção de usina hidroelétrica para a Região Norte, apenas sinalizou a possibilidade de se construir usinas em locais inventariados ${ }^{40}$, bem como se tentou conciliar a construção simultânea de dois sistemas e, também, propôs a entrada em operação da interligação Sul-Sudeste, em 1981, a conclusão da primeira linha de $750 \mathrm{kv}$ e do circuito de corrente contínua entre as subestações de Foz de Iguaçu (PR) e Ibiúna (SP), ambos previstos para o ano de 1983, entre outras previsões estabelecidas.

O quadro a seguir apresenta um resumo das projeções de expansão do sistema elétrico do país, conforme descrito no Plano 95.

Observando os dados que efetivamente descrevem a real situação do setor elétrico nesse período, pode-se destacar que o consumo total de energia elétrica no ano de 1985 foi 173.564 GWh. Logo, observa-se uma variação negativa de 14,9\% quando comparado ao que foi projetado no Plano 95 para este ano.

No ano de 1990, o consumo total foi de $217.657 \mathrm{GWh}$, resultando também em um número menor ao que foi apresentado no Quadro 1, de -29,1\%.

\footnotetext{
${ }^{39}$ A taxa de crescimento anual do PIB no período 1979 a 1995 foi de 2,5\%, bem inferior a estimada pelo Plano 95.

${ }^{40}$ Como Balbina (AM) e Samuel (RO), visando o suprimento de eletricidade às áreas de Manaus e Porto Velho/Rio Branco, que até então eram supridas por suínas termelétricas a base de derivados de petróleo (Ibid., 2002).
} 
Quadro 1 - Projeção de crescimento do consumo de energia elétrica de acordo com o Plano 95 - período 1985-1995

\begin{tabular}{|c|c|c|}
\hline \multicolumn{3}{|c|}{ Crescimento do consumo de energia elétrica (\%) } \\
\hline Até 1985 & 1985-1990 & 1990-1995 \\
\hline 12,7 & 8,2 & 7,4 \\
\hline \multicolumn{3}{|c|}{ Estudo de mercado } \\
\hline 1979-1981 & 1982-1983 & 1984-1(996̆tinuação) \\
\hline $\begin{array}{c}\text { Projeção de consumo com base } \\
\text { no trabalho plante }{ }^{41} \\
\text { (Planejamento de tarifas de } \\
\text { energia elétrica) }\end{array}$ & $\begin{array}{c}\text { Desdobramento dos valores } \\
\text { globais aprovados para o Plante }\end{array}$ & $\begin{array}{l}\text { (Continua) } \\
\text { Metodologia geral empregada em } \\
\text { estudos anteriores da Eletrobrás }\end{array}$ \\
\hline \multicolumn{3}{|c|}{ Mercado provável (GWh) } \\
\hline 1985 & 1990 & 1995 \\
\hline 204.000 & 307.000 & 440.000 \\
\hline \multicolumn{3}{|c|}{ Programação da expansão dos sistemas elétricos ${ }^{42}$} \\
\hline \multicolumn{2}{|c|}{ Mercado de programação $0^{43}(\%)$} & lercado provável (\%) \\
\hline 12,7 & \multicolumn{2}{|r|}{11,3} \\
\hline \multicolumn{3}{|c|}{ Expansão dos sistemas interligados - disponibilidade adicional (MW) } \\
\hline \multicolumn{2}{|l|}{ 1986-1990 } & 1991-1995 \\
\hline \multicolumn{2}{|l|}{15.000} & $31.000^{44}$ \\
\hline \multicolumn{3}{|c|}{ Capacidade de geração de energia elétrica (MW) } \\
\hline \multicolumn{2}{|l|}{1990} & 1991-1995 \\
\hline 71.177 & 50.000 & \\
\hline
\end{tabular}

Fonte: Cachapuz, 2002, p. 131-144

No tocante a capacidade instalada, os dados da EPE (2013) revelam que a capacidade instalada no ano de 1990 foi de 53.050 MW, cuja participação da

41 Publicado em 1978 pelo MME e pelo Departamento Nacional de Águas e Energia Elétrica (CACHAPUZ, 2002).

${ }_{2}$ Programação de obras: Interligação no curto prazo dos sistemas elétricos das regiões Sul e Sudeste e das regiões Norte e Nordeste; O mercado de energia elétrica foi dividido em três segmentos básicos: sistema interligado Sul/Sudeste/Centro-Oeste; sistema interligado Norte/Nordeste, abrangendo os estados nordestinos e parte do Estado do Pará; sistemas isolados da Amazônia (CACHAPUZ, 2002).

43 Projeção de mercado mais elevado, que foi elaborado tomando-se como base estimativas de crescimento mais acelerado da economia e/ou substituição de pequena parcela do consumo de derivados de petróleo por energia elétrica (Ibid., 2002).

${ }^{44}$ Mediante a combinação dos recursos energéticos disponíveis: potencial hidrelétrico (do qual restariam ainda $63.000 \mathrm{MW}$ médios a ser aproveitados (sem levar em conta os aproveitamentos da margem esquerda do Amazonas), o carvão da região Sul e de outras fontes renováveis, solar, eólica e marés, sem viabilidade comprovada para produção industrial em grande escala, não constituindo recursos significativos para a geração de energia elétrica até 1995 (Ibid., 2002). 
hidroeletricidade foi de 85,9\%. Entre 1991 e 1995, a capacidade instalada avançou de 54.141 MW em 1991, para 59.122 MW em 1995. Só a potência instalada de hidroeletricidade passaria de $45.992 \mathrm{MW}$ para 50.680 no mesmo período. Em 1990, a capacidade instalada de geração elétrica no país já era quase 2,5 vezes a potência instalada em 1975.

O programa de obras em andamento acrescentaria $33.344 \mathrm{MW}$, compostos por 27.039 MW nos sistemas interligados, 6.300 MW da potência instalada de Itaipu pertencente ao Brasil, além dos $5 \mathrm{MW}$ dos sistemas isolados. As obras adicionadas acrescentariam $18.850 \mathrm{MW}$, incluindo $445 \mathrm{MW}$ estimados para os sistemas isolados da Amazônia (CACHAPUZ, 2002, p. 143-144).

Em termos de participação, a fonte hídrica representou em 1975 um percentual de $77,8 \%$, mas que ao longo do período 1975-1995 sua participação foi expandindo, chegando em 1995 a representar $86,9 \%$ do total da potência instalada de geração elétrica no país. Interessante notar a participação da termoeletricidade, que, de 22,2\% em 1975, alcançou 20 anos depois um percentual de 12,0\%. Estas são, portanto, as duas fontes principais de geração de eletricidade nesse período.

No que se refere a taxa de crescimento anual, destaca-se que no período 19751985, a taxa de crescimento do consumo total foi de 9,5\%, em virtude do desempenho das indústrias de bens intermediários, com projetos em maturação do início da década de 1980 (LIMA, 1995). Portanto, tal percentual é a projeção realizada pelo Plano 95, enquanto a taxa de crescimento anual do consumo total, verificada no período 19791985 , foi de $7,7 \%$.

Desse modo, pode-se assinalar que, após a fase de implantação dos projetos industriais considerados no II PND, as taxas de crescimento do consumo de energia elétrica foram amortecidas. Contudo, constatou-se também, conforme a análise dos dados da EPE (2013) e MME (2013), que a taxa de crescimento anual do consumo de energia elétrica para o período $1985-1990$ foi de $4,6 \%$, ou seja, muito inferior ao projetado pelo Plano 95 (Quadro 1).

De igual modo, verifica-se também a taxa de crescimento anual do consumo total de energia elétrica no período 1990-1995, que foi de $4 \%$, bem inferior ao que foi estimado.Os dados revelaram ainda que a taxa de crescimento anual dos acréscimos 
de capacidade instalada, consumo total e OIEE apresentaram percentuais negativos no período 1985/1990, mas que recuperaram sua capacidade de acrescentar capacidade de geração de energia elétrica no período 1990 a 1995, graças aos investimentos realizados/concluídos referentes às projeções realizadas nos planos anteriores.

As projeções realizadas no Plano 95 foram condizentes com outras já realizadas em planos anteriores e a potencialidade de geração de energia elétrica já estudada e inventariada, de modo que se configuraria, a partir dessas estimativas, um planejamento mais amplo, englobando tanto o sistema interligado como o isolado, manifestando, assim, o desejo de se construir novas centrais geradoras e novas projeções para a década de 1980.

Foi nesse sentido que, na década de 1980, foi criado o Grupo Coordenador do Planejamento dos Sistemas Elétricos (GCPS) ${ }^{45}$, cujo objetivo principal era planejar a expansão do sistema de energia de forma determinativa ${ }^{46}$, fazendo com que o planejamento setorial passasse por novo processo de evolução importante. Com isso, as empresas produtoras comercializadoras, concessionárias, vendendo ou não energia, eram obrigados a seguir as metas propostas (BAJAY, 2002).

A constituição do GCPS, oficialmente em 1982, visava:

Estudar alternativas de desenvolvimento dos sistemas elétricos das concessionárias e elaborar pareceres e proposições para ajustar os programas de expansão das empresas, entre si e às diretrizes fixadas e pela Eletrobrás, assegurando sua compatibilidade com a política energética governamental (CACHAPUZ, 2002, p. 176).

Além do mais, o GCPS se encarregava do planejamento da expansão do sistema, aperfeiçoando, assim, a forma de planejamento em curso, tendo como base uma forma de planejamento determinativo, como já enfatizado. O planejamento determinativo previa com exatidão previsões e ajustes necessários à construção de obras de geração e transmissão projetadas (GOLDENBERG \& PRADO, 2003), bem como configurava uma sustentação dos planejamentos e projeções realizadas,

${ }^{45}$ Coordenado pela Eletrobrás, contou com a participação de empresas estaduais, municipais, federais, e, também, com a iniciativa privada (GOLDENBERG \& PRADO, 2003).

${ }^{46}$ No entanto, o processo de elaboração do planejamento era participativo, uma vez que todas as empresas do país, geradoras ou distribuidoras tinham acento no fórum das discussões. Os dados e as informações técnicas utilizados pelos comitês técnicos eram de livre acesso a todos os participantes, assim como as metodologias de trabalho utilizadas (GOLDENBERG \& PRADO, 2003, p. 220). 
determinando o horizonte de obras a serem executadas com vistas à expansão do sistema elétrico do país, notadamente no que tange a transmissão e geração de eletricidade.

Segundo Cachapuz (2002), o GCPS passou assumir de imediato as atividades de planejamento de curto prazo, desenvolvendo estudos de periodicidade anual e, por isso, não participou da elaboração do Plano Nacional de Energia Elétrica, iniciado pela Eletrobrás e concluído em 1982 com o nome Plano de Suprimento aos Requisitos de Energia Elétrica até o ano 2000 (Plano 2000).

\subsection{O PLANO 2000}

O Plano 2000 significou uma revisão do Plano 95 em razão da crise econômica nacional, que impôs sérias dificuldades às metas estipuladas naquele plano por conta dos cortes orçamentários, afetando principalmente as projeções que haviam sido realizadas para as obras dos sistemas de transmissão em corrente alternada ${ }^{47}$.

Segundo os dados do MME (2013), a taxa de crescimento do consumo de energia elétrica aumentou $12 \%$ no período 1970-1980; no ano de 1981, essa variação fora de apenas 2,9\%, em relação ao ano de 1980, que foi de 10,5\%. Esta realidade vai impactar a consecução das novas estimativas do mercado de energia elétrica que o Plano 2000 considerou.

Da mesma forma, a taxa de crescimento anual do PIB, segundo os dados do IPEA, que, no mesmo período foi de $8,6 \%$, no ano de 1981 , apresentou uma variação anual, em relação a 1980 , de $-4,25 \%$. Ou seja, de acordo com a Eletrobrás, o novo contexto sinalizava um ambiente de incerteza sobre a retomada do processo de desenvolvimento do país e, consequentemente, sobre o mercado de energia elétrica (CACHAPUZ, 2002).

O referido plano significou a implementação de um programa abrangente de obras de expansão dos sistemas elétricos,

${ }^{47}$ Cachapuz (2002, p. 181) destaca que a construção do trecho inicial entre Foz do Iguaçu e Ivaiporã foi suspensa e a inauguração do trecho entre Ivaiporã e Tijuco Preto foi adiada para o ano de 1982. 
Abarcando os sistemas elétricos regionais em seu conjunto e incorporando outros aspectos da expansão, como a dimensão financeira dos investimentos, o grave quadro de estrangulamento econômico-financeiro do país, em geral, e do setor de energia elétrica, em particular (LIMA, 1995, p. 122).

As premissas básicas do plano, de acordo com a análise de Cachapuz (2002), levaram em consideração as diretrizes governamentais de intensificação do uso do carvão nacional| ${ }^{48}$, o alongamento do prazo de construção de algumas obras e o impacto da recessão econômica, o que contribuiu para o arrefecimento das novas projeções e com maior veemência para a dificuldade de se implementar um planejamento integrado de longo prazo.

O Plano 2000, na mesma linha que vinha sendo defendida desde o Plano 95, considerou a necessidade de implantar uma política de substituição de petróleo por eletricidade nos principais setores industriais, o que elevaria a taxa de crescimento médio anual do mercado de energia elétrica do país para 8\% ao ano até o ano 2000.

Em termos de taxas médias de crescimento do consumo de energia elétrica, a previsão realizada foi que haveria um aumento de $7,7 \%{ }^{49}$, no período 1980 a 1984 , $10,5 \%{ }^{50}$, nos anos 1984 a 1990, 7,0\% ${ }^{51}$, em 1990-1995 e de $6,2 \%{ }^{52}$, entre 1995 e 2000 , tendo o consumo residencial ${ }^{53}$ uma participação de $21,1 \%$, em 1980 , e de $16,6 \%$, em 2000 , enquanto que o consumo industrial ${ }^{54}$ passaria de $54,1 \%$, em 1980 , para $62,9 \%$, em 2000 e o consumo comercial e de outras categorias ${ }^{55}$ aumentariam sua participação de $9,4 \%$, em 1980 , para $11,1 \%$, em 2000 .

\footnotetext{
${ }^{48} \mathrm{Em} 1980$ havia sido encaminhado à Eletrobrás o programa de usinas termelétricas a carvão, aprovado pelo governo, propondo a criação de dois polos de desenvolvimento de tecnologia e de infraestrutura industrial, um no Rio Grande do Sul (RS), e outro em Santa Catarina (SC). Também fora previsto a construção de novas termelétricas a cada dois anos, a partir de 1981, sendo duas unidades de $300 \mathrm{MW}$ no RS e uma de $300 \mathrm{MW}$ em SC (CACHAPUZ, 2002).

${ }^{49}$ Pelos dados do MME (2013), a taxa de crescimento anual do consumo de energia elétrica no período de 1980 a 1984 foi de $6,9 \%$.

${ }^{50}$ A taxa de crescimento anual do consumo de energia elétrica para o período 1984 a 1990 foi de 5,3\%.

${ }^{51}$ A taxa de crescimento anual do consumo de energia elétrica para o período 1990 a 1995 foi de $4,0 \%$.

${ }^{52}$ A taxa de crescimento anual do consumo de energia elétrica para o período 1995 a 2000 foi de 4,6\%.

53 De fato, o que ocorreu nessa categoria de consumo foi um aumento percentual de participação, passando de $19 \%$, em 1980, para 25,2\%, em 2000.

${ }^{54}$ No tocante ao setor industrial, os dados mostram uma diminuição percentual de participação. Ou seja, de $55,6 \%$, em 1980 , para $44,2 \%$, em 2000.

${ }^{55} \mathrm{O}$ setor comercial teve uma participação no consumo final de energia elétrica de $11,2 \%$, em 1980, e $14,3 \%$, em 2000. Somando as categorias de consumo comercial, setor energético, público, agropecuário e transportes, a participação foi de 25,4\%, em 1980, e 30,5\%, em 2000.
} 
Todas as projeções realizadas para o potencial de energia elétrica existente no país, bem como sobre a capacidade de geração de energia elétrica, indicavam que haveria um ambicioso programa de obras de geração de eletricidade, divididos em três etapas (CACHAPUZ, 2002) ${ }^{56}$ :

I. Programa recomendado de expansão da capacidade geradora até $1985^{57}$, que agregaria $44.700 \mathrm{MW}$ à potência instalada, sendo 10.730 correspondente ao sistema interligado Norte/Nordeste, 31.240 MW ao sistema interligado Sul/Sudeste/CentroOeste e o restante seria computado pelos sistemas isolados da Região Norte;

II. Programa de referência de geração dos sistemas interligados até 1995 (Ibid., 2002), que previu a continuidade de implantação dos programas nuclear e do carvão mineral, o aproveitamento dos potenciais hidroelétricos ainda disponíveis nas regiões Sul, Sudeste e Centro-Oeste, a ampliação da usina Tucuruí e a construção da Usina Pão de Açúcar, no rio São Francisco. Destaca-se ainda o caráter indicativo do programa, em virtude "do grau de incerteza quanto às tendências de crescimento do mercado de energia elétrica no período de longo prazo [...]" (CACHAPUZ, 2002, p. 200);

III. Programa de referência de geração dos sistemas interligados de 1996 a 2000, que estabelecia um cenário de importante para o período 1996 a 2000, tendo como "premissa básica a instalação de mais três centrais nucleares na Região Sudeste e quatro unidades a carvão na Região Sul" (Ibid., 2002, p. 203), além de admitir, em princípio, por meio da interligação Norte/Sudeste, que seria, sem dúvida, o investimento de maior importância previsto no plano $2000^{58}$, a complementação do suprimento de eletricidade para a Região Sudeste a partir da Região Norte (notadamente através das bacias do Alto Tocantins/Araguaia e do rio Xingu).

\footnotetext{
${ }^{56}$ Mais detalhes sobre esses programas, ver Cachapuz (2002, p. 189-204).

${ }^{57}$ Segundo Cachapuz (2002), esse programa foi condicionado pela redução do ritmo de crescimento do mercado e pela reprogramação de usinas hidrelétricas, bem como levou em conta a expansão termelétrica previamente aprovado pelo MME, compreendendo a instalação de 11 usinas termelétricas a carvão e $335 \mathrm{MW}$ e oito centrais nucleares de $1.300 \mathrm{MW}$ até o ano 2000.

58 No tocante a outros investimentos em transmissão previsto no Plano 2000, destaca-se o desenvolvimento de interligações regionais de grande porte, bem como tinha-se como base na programação dos investimentos em transmissão "as condições de suprimento aos principais centros de carga de cada sistema interligado, a entrada em operação de novas usinas hidrelétricas termelétricas e a evolução de capacidade das interligações inter-regionais" (CACHAPUZ, 2002, p. 205).
} 
Contudo, a década de 1980, em função da crise das dívidas internas e externas, dificultou a realização dos programas previstos, e com isso, tiveram que ser revisados todas as projeções destacadas, resultando no agravamento do sistema de planejamento setorial, que teve que enfrentar enormes dificuldades para reduzir os investimentos do setor de energia elétrica e, ao mesmo tempo, garantir a oferta interna desse serviço de forma condizente com o processo de substituição de importações de petróleo, contemplado no plano em tela (CACHAPUZ, 2002).

Tudo isso acabou comprometendo a taxa de crescimento anual da capacidade instalada de energia elétrica. No período de 1974 a 1982, essa taxa foi de 10,2\% a.a., passando de 18.133 MW em 1974, para 39.346 MW em 1982. A partir desse ano o ritmo de crescimento da capacidade instalada sofreu redução, em termos de taxa de crescimento anual.

No período considerado no programa obras, registra-se que entre 1981 e 1985 a capacidade instalada cresceu a uma taxa anual de 4,3\%; entre 1985 e 1995, a capacidade instalada cresceu a uma taxa anual de 3,0\% e; no período 1996 a 2000, a taxa de crescimento anual da capacidade instalada foi de $4,9 \%$.

No ano de 1982 destaca-se ainda como parte do Plano 2000 e considerando a nova conjuntura de recessão econômico-financeiro, a conclusão pela Eletrobrás do Manual de Estudos e Projetos de Pequenas Centrais Hidrelétricas $(\mathrm{PCH})$, que não apenas consolidaria a tecnologia do país sobre a construção de hidrelétricas de pequeno porte, como também "poderiam prestar importante contribuição à política brasileira de substituição do petróleo, assumindo o lugar de pequenas instalações geradoras térmicas acionadas a óleo diesel (CACHAPUZ, 2002, p. 214).

De acordo com o autor em tela, já em 1983 destaca-se, dentre outras atividades de planejamento, o Manual de Inventário de Bacias Hidrográficas, de modo a atualizar os estudos realizados no ano de 1977 e a conclusão de um trabalho sob o título Instruções para os estudos de viabilidade de aproveitamentos hidrelétricos, objetivando elaborar um roteiro que servisse de base "para a programação, contratação, controle de execução e verificação da qualidade de estudos de viabilidade" (CACHAPUZ, 2002, p. 218). 
Em 1985, foi realizado a atualização do Plano 2000, um ano antes do previsto, pelo grupo misto integrado por representantes do GCPS/GCOI, constituído nesse mesmo ano. Um dos pontos importantes dessa revisão foi a substituição do critério de garantia de surgimento de energia elétrica ${ }^{59}$ por outro formulado pelo critério probabilístico (CACHAPUZ, 2002). Com esse novo critério, ganha importância as informações sobre a hidrologia brasileira, que, tendo como base um modelo estatístico que se alimentava com os dados dessa hidrologia, era possível fazer simulações, de modo a racionalizar o uso da energia elétrica colocada no sistema. Ou seja:

Toda vez que as simulações mostravam um risco de ocorrência de déficit futuro maior do que 5 por cento, estava na hora construir uma nova hidrelétrica. $E$, se por falta de chuvas, o déficit nos fazia aproximar de 5 por cento de risco no presente, estava na hora de ligar usinas térmicas ${ }^{60}$, que formam o "banco de reservas" do sistema (BENJAMIN, 2001, p. 10).

Segundo Leite (2007), a previsão de risco que era, inicialmente, da ordem de $3 \%$, com a entrada em operação da usina hidrelétrica de Itaipu, com suas linhas de integração do sistema, e o aperfeiçoamento dos modelos probabilísticos ${ }^{61}$ passa a ser estimada para $5 \%$, correspondendo ao risco tolerável de energia assegurada pelo sistema. Segundo Benjamin (2001), essa forma de planejamento para um período de cinco anos permitia que se pudesse garantir o suprimento dessa energia de modo confiável. Ou seja, a demanda prevista para esse período permanecia sempre igual à "energia firme" 62 com uma taxa de risco estipulada em 5 por cento.

O GCPS passou assumir várias funções em meados da década de 80 , além do que já realizava, como os programas e planos decenais de geração, transmissão e

\footnotetext{
${ }^{59}$ Pelo critério tradicional, a capacidade de produção de energia era determinada de modo a garantir o suprimento de energia sem ocorrências de déficits de eletricidade na hipótese de repetição do registro histórico de vazões (CACHAPUZ, 2002).

${ }^{60}$ A participação das usinas térmicas na capacidade nacional de geração, nela incluída a quota-parte de Itaipu, que cabe ao Brasil, foi decrescente desde 1972, até chegar um mínimo de 12,6\%, em 1996, passando então a crescer lentamente, com o reforço da consistente entrada de usinas a gás natural, em 2001 (LEITE, 2007, p. 295).

${ }^{61}$ Empregou-se primeiramente, em 1990, o Modelo de Despacho de Sistemas Hidrotérmicos (MODDHT). Ainda na década de 90, o Centro de Pesquisa de Energia Elétrica (CEPEL) pesquisou modelos operacionais mais condizentes com o sistema hidrotérmico implantado no país, surgindo o primeiro modelo Dinâmico, baseado em programação estocástica, cuja aplicação estendeu até 1998 (LEITE, 2007).

${ }^{62}$ A energia firme de uma usina hidrelétrica corresponde à máxima produção contínua de energia que pode ser obtida, supondo a ocorrência da sequência mais seca registrada no histórico de vazões do rio onde ela está instalada (ANEEL, 2005, p. 9).
} 
distribuição, passou a se encarregar da elaboração dos planos estaduais ou de territórios federais instituídos por portarias do DNAEE como parte da "necessidade de uma tradução do planejamento setorial num documento de transito mais amplo ao nível político-institucional" (JOSÉ LUIZ ALQUÉRES Apud CACHAPUZ, 2002, p. 220).

É importante destacar que a Eletrobrás nesse momento se viu na eminência de ter que resolver problemas financeiros decorrentes da recessão econômica, de como alocar recursos para a realização de investimentos necessários.

O setor elétrico fora afetado sobremaneira e o que é mais preocupante as obras previstas nos planos, tanto no Plano 95 como no Plano 2000, configuravam uma preocupação porque os recursos encontravam-se escassos, principalmente a partir de 1982, dificultando a realização dos investimentos previstos e necessários à expansão do sistema elétrico do país, que agora contava com um setor industrial relativamente pujante e fortemente demandante de eletricidade (cujo peso no consumo final de energia elétrica, salta de $40 \%$, em 1970 , para aproximadamente $54 \%$, no final da década de 1980), um segmento residencial que passou a consumir mais energia, chegando ao final da década de 1980 com uma participação no consumo final de eletricidade de 20,6\%, em virtude do aumento do grau de urbanização e do consumo de bens e serviços mais intensivos em energia elétrica, além do setor comercial e outros.

Tudo isso pressionava o sistema elétrico para disponibilizar uma oferta de eletricidade capaz de alimentar a complementação do processo de industrialização em curso. Sendo assim, a tarefa do planejamento nesse setor tinha como meta assegurar que esse suprimento de energia elétrica permanece sustentável dentro de uma potencialidade de geração de eletricidade já constatada e inventariada.

Contudo, a década de 1980 acabou colocando um ponto de inflexão nesses projetos e estudos realizados, como se já começasse nesse período uma reorganização de metas que estaria na contramão da necessidade do sistema elétrico.

Isso é fruto da própria ideia de planejamento que se cria nesse período, completamente desarticulado com os objetivos envidados nos planos de desenvolvimento econômico, sendo estes agora frutos de uma nova conjuntura que privilegia menos a expansão da atividade produtiva e mais os objetivos ligados a dimensão econômico-financeira. Tanto é que o III Plano Nacional de Desenvolvimento 
(1980/1985) e o I Plano Nacional de Desenvolvimento da Nova República (I PND-NR, de 1985/1989) não saíram do papel (ALMEIDA, 2006).

Portanto, existia um ambiente cujo interesse maior era resolver/atenuar a instabilidade macroeconômica nos quesitos principais - crise da dívida e inflação alta e com isso a atividade de "planejamento" da economia como um todo se resume em introduzir planos de estabilização econômica, dando continuidade ao que se vinha implantando no começo da década de 1980, ou seja, um "processo de esvaziamento do planejamento enquanto lugar central das decisões de política econômica e de coordenação das ações empreendidas pelo governo" (REZENDE, 2009, p. 8).

Sob esse novo ambiente, o GCPS passou a ter que contar em suas decisões com uma conjuntura desfavorável ao processo de realização de todos os investimentos necessários à expansão da geração e transmissão de energia elétrica. A reformulação do Plano 2000 acaba retardando vários dos projetos que se tinha planejado, e já, em 1984, os investimentos globais do setor reduziram 10,5\% em comparação com o ano de 1983 (CACHAPUZ, 2002). Ou seja, o GCPS passou a enfrentar uma dificuldade de como planejar os investimentos do setor de modo a manter a oferta de eletricidade necessária ao país, mas dentro de um contexto de escassez de recursos.

E o que é mais grave, o Comitê Técnico de Estudos Energéticos (CTEE), que aprovou os programas decenais de geração dos sistemas interligados do período 19851994, destacou que as conclusões sobre o suprimento de eletricidade para o sistema interligado Sul/Sudeste/Centro-Oeste estavam apresentando risco anuais de déficit de eletricidade acima de $10 \%$ em todo o período da simulação probabilística, atingindo cerca de 20\% em 1988 (CACHAPUZ, 2002), portanto, apresenta um risco acima dos $5 \%$ previsto pelo GCPS.

Logo, "como o programa de expansão não estava ajustado aos requisitos de energia, constatou-se insuficiência de reserva para o atendimento de ponta" (CACHAPUZ, 2002, p. 222). Para o sistema interligado Norte/Nordeste, apenas para o ano de 1990 se verificou pelas simulações probabilísticas possibilidade de ocorrência de déficit não eliminado pela operação de geração térmica disponível.

Procurando atenuar essa crise que assolava o setor de energia elétrica, fora retomado, no governo Sarney, o Plano de Recuperação Financeira do Setor Elétrico 
(PRS), aprovado em 1985, que buscava implementar algumas medidas com vistas a atenuar o problema do setor nos aspectos financeiros, de suprimento de eletricidade e de adequação do setor as novas medidas contempladas no período da Nova República, abrangendo o período de 1986 a 1989, mas não resolveu os problemas detectados e logo após a sua aprovação o governo teve que tomar medidas restritivas ao suprimento de energia elétrica na Região Sul, nos primeiros meses do ano de 1986.

Já na Região Sudeste, a ameaça de racionamento foi controlada em função da "melhoria das condições hidrológicas, da conclusão da primeira linha alternada do sistema de transmissão de Itaipu e a chegada da energia produzida pelas duas primeiras máquinas de $60 \mathrm{~Hz}$ da usina binacional" (CACHAPUZ, 2002, p. 239), diferentemente da Região Nordeste, o sul do Pará e o norte de Goiás, que enfrentaram racionamento, em 1987.

\subsection{O PLANO 2010}

Por tudo isso, o referido plano foi revisado em 1986 e aprovado em 1987, procurando reaver a ideia de planejamento anteriormente contemplado nos estudos e elaboração dos planos de expansão do setor de energia elétrica, de modo a adequá-lo melhor às necessidades de curto prazo do setor em tela, bem como, em 1987, foi elaborado um plano de longo prazo, conhecido como Plano 2010, que visava efetuar um Plano Nacional de Energia Elétrica 1987/2010. Os objetivos principais desse plano eram traçar trajetórias de referência para a evolução do setor de Energia Elétrica, evidenciar as principais opções que se apresentam aos agentes envolvidos e motivar a oportuna tomada de decisões, com o necessário grau de reflexão e avaliação técnica (MME, ELETROBRÁS, 1987).

De modo singular, o referido plano buscava, ademais, "consolidar, na forma de um plano diretor, as ações relativas à preservação do meio ambiente e à inserção regional dos empreendimentos, definindo recursos e meios para sua efetivação" (Ibid., p. 7). Isso significava que o planejamento, a essa altura, representava algo muito mais que realizar projeções que pudessem nortear a política do setor de energia elétrica no período considerado, mas que tratava de forma conexa aspectos inerentes às estimativas de expansão da geração de eletricidade do país, buscando incluir metas 
importantes ao processo de continuidade do desenvolvimento do setor, principalmente tinha-se muito claro os problemas inerentes à realização de um plano de longo prazo, em virtude do grau de incerteza que envolve às projeções realizadas (CACHAPUZ, 2002).

Em adição, constata-se que, por meio do Plano 2010, é retomado com maior nitidez, na primeira metade da década de 1990, a preocupação com o meio ambiente, que, iniciada na década de 1970, trazia, desde o final da década de 1980, iniciativas tomadas pelo MME, buscando inserir o setor elétrico dentro do contexto ambiental: a constituição do Comitê Coordenador das Atividades do Meio Ambiente do Setor Elétrico (COMASE), em 1988; constituição de órgãos específicos da estrutura administrativa da Petrobrás e Eletrobrás; constituição do Comitê Consultivo do Meio Ambiente (CCMA) (LEITE, 2007).

Paralelamente, cariaram organizações não-governamentais ligadas ao meio ambiente e já, em 1992, fora dado um passo importante nesse contexto, a Conferência Rio-92. Esta iniciativa veio trazer à discussão o conceito de desenvolvimento sustentável, bem como propostas concentradas na chamada Agenda 21, os quais visam tornar mais enfático a questão do meio ambiente em vários aspectos, mas de modo muito especial, no que diz respeito as emissões de $\mathrm{CO}_{2}$ provenientes do consumo de energia primária.

Destaque importante diz respeito a preocupação com as questões ambientais no âmbito da construção de grandes obras hidrelétricas, o que permitiu que a Eletrobrás inserisse nos seus estudos e planejamento para o setor, a preocupação com a dimensão ambiental em empreendimentos em operação, bem como naqueles relacionados ao Plano de Recuperação Setorial (PRS).

Entretanto, no Plano 2010, que refere-se ao segundo Plano Nacional de Energia Elétrica elaborado para um horizonte de longo prazo, são inseridos discussões que procuram reconhecer nas metas de planejamento de expansão dos sistemas elétricos do país, tanto a dimensão ambiental como a inserção regional como elementos condicionadores dos empreendimentos passíveis de serem implementados no futuro, sendo considerado o primeiro plano nacional de energia elétrica à incluir na implementação de um planejamento de longo prazo para o setor "os impactos sociais e 
ambientais inerentes à implantação de usinas e linhas de transmissão (CACHAPUZ, 2006, p. 307).

Portanto, o Plano 2010 configurava-se, de modo diferenciado, por entender que a atividade de planejamento se efetua em caráter contínuo dentro da rotina da Eletrobrás e das concessionárias, bem como por apresentar um horizonte de longo prazo, se voltando à análise e investigação de possíveis cenários de desenvolvimento do setor elétrico nacional, procurando concentrar seus esforços nos aspectos conceituais e estratégicos à efetiva expansão do referido setor.

No período 1970 a 1985, a taxa de crescimento anual do consumo de eletricidade foi de $10,4 \%$, enquanto o consumo total de energia e o PIB obtiveram uma taxa de crescimento anual de $4,3 \%$ e $6,1 \%$, respectivamente. A participação da energia elétrica no consumo final de energia passou de 5,5\%, em 1970, para 12,7\%, em 1985.

Merece destaque o aumento da participação do consumo de eletricidade no consumo final de energia e o MME e a Eletrobrás, assinalam, no Plano 2010, fatores conjunturais que explicam esse indicador. Dentre eles convém assinalar o aumento dos derivados de petróleo e um decréscimo do preço da eletricidade, incentivando não apenas a substituição do petróleo por energia elétrica, mas também o uso desmensurado da eletricidade, que teve como instrumento de incentivo o aparecimento das tarifas especiais ${ }^{63}$ e a maturação de grandes projetos de produção de insumos básicos, como alumínio e aço.

Mediante o que foi apresentado, o plano 2010 realizou algumas projeções para o mercado de energia elétrica, considerando os anos 1986/2010 e contando com a participação das concessionárias e do GCPS. Sendo assim, estimou-se uma taxa de crescimento anual do PIB de 5,8\%, no período 1985/2010, bem como de 1,7\% para população total e 4,1\% de PIB per capita. Com isso, o PIB passaria de $226,610^{9}$ US\$ (a preços de 1985), em 1985, para $918,610^{9}$ US $\$$, logo uma variação de $305,4 \%$; a população passaria de $135.56410^{3}$ hab. para $207.45410^{3}$ hab., com variação de 53\%; já o PIB per capita passaria de 1.672 US\$/hab. para 4.428 US\$/hab.

${ }^{63}$ Estabelecidas com valores até cinco vezes menores que os níveis tarifários normais, elas visavam incentivar a substituição dos derivados de petróleo e as exportações, o que, mesmo sem outros fatores adicionais, seria um motivo para o grande aumento no consumo de eletricidade (MME, ELETROBRÁS, 1987). 
Tais projeções perfizeram estimativas do consumo total de energia elétrica no país de 175,7 TWh, em 1986, para 668,8 TWh, cuja variação anual indica um percentual de 280,6\%; as taxas geométricas médias anuais foram estimadas em 5 períodos: 1990/1986 7,4\%, 1995/1990 6,5\%, 2000/1995 5,6\%, 2005/2000 5,1\%, $2010 / 20054,4 \%$.

Em termos de participação no consumo no total de energia elétrica, evidenciavase maior participação da região Sudeste + Centro-Oeste - MS, a despeito de redução de participação durante o período, que passaria de $67,8 \%$, em 1986, para 56,2\%, em 2010; já a região Sul + MS, sua participação passaria de 13,7\% para 18,2\%; Nordeste MA, de 13,2\% para 15,9\%; e Norte + MA, 5,3\% para 9,7\% no mesmo período.

No tocante ao consumo de energia elétrica, percebe-se uma redução de suas estimativas de crescimento, muito embora essa seja resultado não apenas do período de ajustamento porque passará a economia brasileira, mas também de maturidade do mercado de energia elétrica, com a pressuposição de "ocorrência simultânea de uma perda de peso relativo dos setores industriais intensivos em energia elétrica, uma tendência à saturação dos consumos residencial e do setor de serviços, e a efetiva implantação de políticas de conservação de energia ${ }^{64 "}$ (MME, ELETROBRÁS, 1987, p. 18).

Com relação ao PIB, este indicador não atingiria um percentual de mais de 6,8\%, como o previsto para 1985/90, destacando-se, assim, que, na década de 1990, haveria um arrefecimento da expansão dessas taxas que não passaria dos $6,1 \%$, atingindo, $5,8 \%$ no período considerado de $1985 / 10$, como destacado. O documento (Plano 2010) assinala que essas estimativas de crescimento percentual do PIB poderão não se realizar na medida em que sejam superadas as dificuldades do país trazidas na década de 1980, de modo que o país voltaria a apresentar taxas históricas de crescimento, tais como as verificadas no período do pós-guerra, ou seja, cerca de $7 \%$ ao ano.

Para fazer face às estimativas realizadas para o mercado de energia elétrica, contou-se com o potencial e custos das principais fontes de geração disponíveis para o suprimento de eletricidade no período considerado, conforme se observa na Tabela 1. Esses dados revelam o potencial avaliado passível de ser gerada anualmente.

\footnotetext{
${ }^{64}$ Por meio da criação, em 1985, do Programa Nacional de Conservação de Energia Elétrica (Procel).
} 
Tabela 1 - Potencial e custo das principais fontes de geração

\begin{tabular}{lcc}
\hline \multicolumn{1}{c}{ Fonte } & Potencial avaliado (TWh/ano) & Faixa de custo (US\$/MWh) \\
\hline Hidroeletricidade & 765 & $15 / 50$ \\
Carvão** $^{*}$ & 246 & $38 / 48$ \\
Nuclear $^{* *}$ & 137 & 50 \\
Gás natural*** $^{*}$ & Não estimado & 70 \\
Der. de petróleo*** & Não estimado & 70 \\
Biomassa Florestal & Não estimado & 79 \\
\hline
\end{tabular}

Fonte: MME, ELETROBRÁS, 1987

* Não há limite temporal para a geração de energia diante de seu caráter renovável.

** Os valores representam a energia passível de ser gerada anualmente durante 25 anos de vida útil das usinas.

${ }^{* * *}$ Foi considerado um preço de petróleo de US\$30/barril

Das fontes apresentadas somente a hidroeletricidade, o carvão e a nuclear, possuem, no período analisado, possibilidade de contribuírem para a expansão do parque gerador de eletricidade até 2010. Contudo, segundo o referido documento, isso não significava que outras fontes não viessem a fazer parte de estudos e pesquisas, visando obter informações sobre sua potencialidade de produção. Além do mais, "algumas destas fontes, mesmo que não venham a participar pesadamente no balanço energético nacional, poderão vir a se tornar importantes do ponto de vista local e regional" (Ibid., p. 21).

Em termos de potencial hidrelétrico passível de ser aproveitado para a geração de energia elétrica, constata-se que o Brasil possui um total de $106.705 \mathrm{MW} /$ ano. Desse total, $33.983 \mathrm{MW} / \mathrm{ano}$ correspondem ao potencial estimado de aproveitamento e 72.722 ao que efetivamente foi inventariado, bem como que o maior potencial estimado encontra-se na região Norte $(66,9 \%)$, nos quais demandarão estudos dos problemas ambientais que poderão ocorrer em virtude da necessidade de ter que inundar áreas relativamente grandes, cobertas pela floresta tropical típica da região.

Não foram apresentados aqui maiores problemas inerentes à viabilização desses projetos, tanto é que se esperam maiores informações decorrentes da observação do comportamento dos reservatórios de Tucuruí (rio Tocantins/PA), Balbina (rio Uatumã, na bacia amazônica) e Samuel (no rio Jamari, RO), haja vista que esses empreendimentos possibilitarão observar os impactos ambientais que esses reservatórios poderão trazer para a região. 
Quanto ao potencial termelétrico a carvão mineral e energia nuclear, foram estimados um potencial total de $46.800 \mathrm{MW}$ para o carvão mineral, estando o maior volume localizado no Rio Grande do Sul (92,7\%) e Santa Catarina (7,3\%) e de $120.100 \mathrm{t}$ de U308, das quais 65.000 estão localizadas nas jazidas de Lagoa Real/BA e Itatiaia/CE.

Sendo assim, a geração de eletricidade, considerando um horizonte de longo prazo, continuaria a depender das fontes hídricas, cuja participação no parque gerador nacional, apesar de sofrer ligeira redução durante o período passaria de um percentual de $90,2 \%$ em 1986, para cerca de $88,6 \%$ em 2010. O acréscimo na geração de eletricidade seria de 117,3 GW no período, atingindo uma quantidade 160,0 GW em 2010, contra 42,7 GW em 1986, logo, a estimativa é de uma variação de $274,7 \%$.

Estimou-se que a maior variação da potência instalada viria das fontes térmicas movidas à carvão e nuclear, $333,3 \%$ no período, bem como o aumento de sua participação no parque gerador total de 1,6\% revelaria um percentual de $11,4 \% \mathrm{em}$ 2010, contra 9,8\% em 1986.

Isso demonstra como o planejamento de longo prazo levou em consideração a necessidade de se manter uma rede de segurança no suprimento de eletricidade, visto que, na década seguinte, o desenvolvimento de um parque termelétrico movido a carvão e nuclear estaria sendo contemplado "em face do provável esgotamento do potencial hidrelétrico competitivo" (CACHAPUZ, 2006, p. 308).

Tal orientação revela, ademais, a preocupação do plano com a necessidade de se planejar uma escala industrial decorrente das opções industriais relacionadas ao parque hidrelétrico e termoelétrico.

Ou seja, a ideia que estava sendo embasada nessas considerações acerca da expansão do parque gerador nacional de eletricidade era, em adição, o desenvolvimento de equipamentos industriais que estivessem relacionados com a opção termelétrica de geração de eletricidade de modo a garantir "uma transição mais harmônica de uma indústria preponderantemente hidrelétrica para outra preponderantemente termelétrica" (MME, ELETROBRÁS, 1987, p. 40).

Isso posto, convém assinalar, ainda, que a evolução do aproveitamento das fontes disponíveis para efeito de geração de eletricidade retrata que, em 2010, 85,8\% 
do potencial hidrelétrico do país seria efetivamente aproveitado, tendo sua distribuição regionalmente apresentado evolução significativa nos percentuais de aproveitamento, chegando em 2010 as estimativas de um mínimo de 78\% de aproveitamento do potencial hidrelétrico na Região Norte a um máximo de $98,6 \%$, na região Nordeste.

O referido plano também previu informações sobre os fluxos elétricos interregionais. Logo, a previsão realizada destacou que as regiões Sudeste e Nordeste seriam importadoras de energia da região Norte, enquanto a região Sul permaneceria como exportadora de eletricidade para a região Sudeste.

No que se refere a expansão de médio prazo do sistema elétrico brasileiro, que abrange um período de 15 anos, o Plano 2010 projetou a construção de 94 empreendimentos hidrelétricos e 14 termelétricos, totalizando uma potência total programada de $56.685 \mathrm{MW}$ referentes aos empreendimentos hidrelétricos e $5.765 \mathrm{MW}$ de termelétricos.

Tais empreendimentos seriam necessários para cobrir um déficit energético projetado em torno de um mínimo de 0 para as regiões Sul, Sudeste + C.Oeste, em 1988, a um máximo de 5\% nessas regiões, em 1994; nas regiões Norte e Nordeste, a previsão foi de um déficit energético de um mínimo de 0, em 1988, para a região Norte, e um máximo de 9\%, nesses mesmo ano, para a região Nordeste, chegando em 1992, com possibilidade de ambas regiões apresentarem um déficit energético de $5 \%$.

Esses empreendimentos, com estimativa de geração de eletricidade até $2001^{65}$, estão distribuídos em 11 bacias na região Sudeste + C. Oeste, 6 bacias na região Sul, 4 bacias na região Norte e 4 na região Nordeste. Os maiores empreendimentos hidrelétricos, acima de $2000 \mathrm{MW}$ de potência programada, estão localizados na região Sul e dizem respeito a usina de Itaipu, na bacia do Paraná, com 8.400 MW de potência; na região Norte, a usina Cararaô (hoje usina de Belo Monte), na bacia do Xingu, no Pará, com 6.300 MW de potência; e na região Nordeste, na bacia do São Francisco-NE, a usina Xingó, com 3.000 MW de potência. As demais usinas hidrelétricas programadas possuem potência entre $30 \mathrm{MW}$ a $1.980 \mathrm{MW}$.

\footnotetext{
${ }^{65}$ A expansão dos sistemas isolados das capitais da Região Norte a programação foi realizada até 1996. Esses mercados, foram responsáveis em 1985 por $1,1 \%$ do mercado total de energia elétrica, consumindo 1,8 TWh. Esses sistemas utilizam unidades térmicas geradoras de eletricidade à base de derivados de petróleo (MME, ELETROBRÁS, 1987).
} 


\subsection{O PLANO 2015}

Já o Plano de 2015, divulgado em 1994, analisou as disponibilidades de recursos energéticas para efeito de geração de eletricidade, se detendo não apenas no caso da hidroeletricidade e termoelétrica à base de carvão e urânio, consideradas as fontes "disponíveis em quantidade suficiente para representar real alternativa de expansão do sistema" (CACHAPUZ, 2002, p. 326), mas também outras potencialidades tecnológicas, tais como, gás natural e fontes não-convencionais, como a biomassa florestal, resíduos de cana-de-açúcar, energia eólica, energia solar e resíduos orgânicos.

Contudo, o referido plano mostrou que essas fontes não-convencionais necessitavam de estudos mais aprofundados, bem como do "desenvolvimento de um projeto-piloto para a comprovação das tecnologias e dos custos dessas opções" (Ibid., p. 327).

A fonte hídrica foi a que a mais se destacou, confirmando a opção da Eletrobrás por este tipo de fonte para efeito de geração de eletricidade, principalmente em virtude de um potencial ainda a aproveitar, existente na região amazônica, e cerca de um terço na Região Sudeste/Centro-Oeste.

Sendo assim, o total do potencial hidrelétrico brasileiro foi estimado em 129 GW/ano, número esse superior ao que foi apresentado no Plano 2010, sendo que o potencial hidrelétrico a aproveitar foi estimado em $102 \mathrm{GW} /$ ano de energia firme e cerca de 205 GW de capacidade instalável. Já o potencial termelétrico das reservas de carvão mineral nacional foi estimado em 29.210 MW, concentrando-se nos Estados Rio Grande do Sul, Santa Catarina e Paraná, que, somado às reservas inferidas e marginal, alcaçaria algo em torno de $59.000 \mathrm{MW}$.

Com base nessas informações, a estratégia de expansão do parque gerador de eletricidade, para o período 2000 a 2015, tomou como base a perspectiva de esgotamento do potencial hidrelétrico do país nacional e, consequentemente, a necessidade de estudar a viabilidade competitiva da transição entre a expansão hidrelétrica até 2010 e a termelétrica a partir desse ano, tal como foi destacado no Plano 2010. 
Nenhuma consideração maior foi dada as fontes não-convencionais, apenas a menção de que era necessário realizar estudos mais adequados que pudessem avaliar essa potencialidade de recursos energéticos provenientes principalmente da biomassa florestal, bagaço de cana e energia eólica. Isso permite destacar que em todos estudos de planejamento realizados para a expansão do parque gerador elétrico do país nos períodos até aqui considerados, constatou-se que a opção de planejamento para a expansão da geração de eletricidade tinha especialmente na hidroeletricidade sua maior relevância e disponibilidade efetiva para que se pudesse considera-la competitiva e, consequentemente, atrativa, às opções de investimento para o setor.

Não havia assim nenhuma política específica que colocasse as outras fontes não-convencionais no patamar das estratégias de expansão do sistema elétrico do país, o que efetivamente dificultou a realização de estudos técnicos mais abrangentes e viáveis necessários à quantificação da potencialidade existente desses recursos para efeito de geração de eletricidade.

Logo, o resultado desse período, com a implantação dos projetos propostos no planejamento setorial, e, considerando apenas as opções tecnológicas convencionais, foi que a capacidade instalada passou de 4.800,1 MW em 1960, para 7.411,0 MW em 1965 , tendo as concessionárias públicas, nesse ano, a participação de $54,6 \%$, as concessionárias privadas, 33,6\% e autoprodutor, 11,8\% (LIMA, 1995), o que demonstra um aumento da participação do setor público que saltou de 6,8\% em 1952, para 54,6\% em 1965.

Já a participação do setor privado passou, nesses mesmos anos, de 82,4\% para $33,6 \%$, logo, os dados mostraram uma nítida consolidação da participação das concessionárias públicas na geração de energia elétrica, quando, desde meados da década de $1950^{66}$, assim como a partir da constituição da Eletrobrás, o setor ganha uma expressão de planejamento de Estado, conseguindo ir se afirmando como um marco das atividades do sistema elétrico, ao mesmo tempo em que adquire estabilidade e segurança no tocante ao suprimento de eletricidade e consecução das obras geradoras.

${ }^{66}$ Convém registrar que o Plano de Metas viabilizou parcela significativa dos programas do CMBEU e dos empreendimentos previstos no Plano Nacional de Eletrificação do segundo governo Vargas, [...], resgatando iniciativas polêmicas pela via dos mecanismos informais de planejamento (LIMA, 1995, p. 72). 
No período de 1965 a 1973, a capacidade instalada de energia elétrica expandiu em 106,8\%, passando de 7.411,0 MW em 1965 para 15.354 MW em 1973; tendo a energia hidráulica uma participação de $81,5 \%$, ao passo que o consumo de eletricidade passou de 22.618 GWh em 1963 para 52.842 GWh em 1973, com crescimento de 133,6\%, tendo o setor industrial uma participação de aproximadamente 54\% (LANDI, 2006). Em termos de taxa de crescimento anual, a capacidade instalada de energia elétrica apresentou um percentual de 9,2\%, entre 1963 e 1973, enquanto o consumo apresentou 8,9\%. Foram adicionados ao sistema elétrico brasileiro, entre 1960 e 1973, 10.554 MW, representando uma taxa de crescimento anual de $9,4 \%$.

No período de 1974 a 1994, a capacidade instalada de eletricidade evoluiu de 18.133 MW para 57.630 MW (EPE, 2012) - um crescimento de aproximadamente $218 \%$. Só a capacidade instalada de Itaipu, em 1990, era de 11.200 MW, e, em 1991, 12.600 MW (MME, 2013).

O consumo de eletricidade passou de $58.741 \mathrm{GWh}$ em 1974 para $249.793 \mathrm{GWh}$ em 1994 - um crescimento de aproximadamente 326\% (LIMA, 1995; EPE, 2012). A taxa de crescimento anual foi de $6,0 \%$ para a expansão da capacidade instalada e de $7,5 \%$ para o consumo.

Só a participação do setor industrial foi de 50,5\%, em 1994. Conforme dados apresentados por Lima (1995), entre os anos de 1974 a 1984, a participação do setor industrial passou de aproximadamente $54 \%$ para $57 \%$, reflexo dos programas considerados nos planos nacionais de desenvolvimento desses períodos em que se verificou a construção de capacidade produtiva nova e, portanto, de sua crescente utilização, pressionando o setor de energia elétrica de modo sincronizado; em 1990, a participação do setor industrial fora cerca de 52\%, reduzindo, assim, sua participação.

O Brasil chegou em 1994 com uma capacidade instalada de hidroeletricidade de 49.921 MW (quase 87\% de participação) e de termoeletricidade de $7.051 \mathrm{MW}$,

Alimentadas com óleo combustível, carvão e óleo diesel (nessa ordem de importância), [...], sendo utilizadas basicamente para o abastecimento de localidades isoladas e para a complementação dos sistemas interligados nos períodos hidrológicos desfavoráveis ou quando da ocorrência de problemas de atendimento em função de restrição de transmissão (CACHAPUZ, 2002, p. 308) 
Foram adicionados ao sistema elétrico brasileiro, no período 1974 a 1984 , 22.963 MW de potência instalada de energia elétrica, cuja taxa de crescimento anual fora de 8,5\%, ao passo que entre 1984 a 1994 foram adicionados $16.534 \mathrm{MW}$, o que representa uma taxa de crescimento anual de $3,4 \%$, bem inferior ao que foi apresentado no período anterior. Isso porque "a crise financeira setorial e a prioridade concedida a Itaipu limitaram bastante a expansão das concessionárias públicas federais e estaduais que integravam o sistema interligado Sul-Sudeste" (CACHAPUZ, 2002, p. $311)^{67}$.

Contudo, o que é importante destacar nesse período como um todo, especialmente a partir da construção de Itaipu e Tucuruír8, é a mudança da configuração do sistema elétrico brasileiro com a construção desses grandes empreendimentos, avançando, assim, também no processo de interligação, o que facilitou a sustentabilidade da transmissão de energia elétrica e sua distribuição no SIN e sistemas isolados (CACHAPUZ, 2002) ${ }^{69}$.

A partir de 1990, o sistema elétrico brasileiro passou por um processo de arrefecimento da sua capacidade instalada de energia elétrica "em decorrência do atraso, paralisação e suspensão de várias obras" (Ibid., 2002, p. 312), ocasionada pela mal sucedida reforma implementada na segunda metade da década de 1990 e que desaguou na "Crise do Apagão", de 2001.

\section{CONCLUSÕES}

É nesse período que de fato se define o tipo de geração de eletricidade que norteará todos os projetos de investimento do SEB. Na década de 1970, a participação da hidroeletricidade já atinge um percentual acima dos 70\%, bem como já está sendo determinado a construção de grandes empreendimentos hidroelétricos de grande porte,

\footnotetext{
${ }^{67}$ Nas regiões Norte e Nordeste, as obras de geração e transmissão foram também postergadas em relação ao planejamento definido pela Eletrobrás e pelo GCPS (CACHAPUZ, 2002).

${ }^{68}$ A usina de Tucuruí começou gerar energia em 1984, respondendo pela maior parcela do aumento da potência instalada do SIN Norte-Nordeste e, em 1990, já atingia a marca de 3.550 MW (Ibid., 2002).

${ }^{69}$ Além desses aproveitamentos hidrelétricos destaca-se a usina nuclear Angra I (Furnas), que começou a operar comercialmente em 1985 e; ampliação da termelétrica de carvão Candiota II (Ibid., 2002).
} 
com a Eletrobrás definindo o tipo de desenvolvimento setorial que se deseja para a geração de eletricidade do país.

Portanto, a especificada do setor elétrico no Brasil nasce nesse momento, qual seja a de um sistema elétrico com características de monopólio natural, dirigido pelo Estado e movido à base da hidroeletricidade, tendo na termoeletricidade apenas um suporte para fazer face aos momentos de hidrologia desfavorável.

Em termos de planejamento setorial integrado, o DNAEE e a Eletrobrás são os órgãos que definiram a opção pela hidroeletricidade, observando a característica singular do país em termos de uma potencialidade hidráulica passível de ser aproveitada para a produção de eletricidade.

Nesse período, a opção por outras fontes renováveis para efeito de geração elétrica fez-se presente apenas como indicação, mas não representava ainda objeto de planejamento e de política específica. Toda a concentração de esforços estava em construir projetos hidrelétricos importantes, como Itaipu, Tucuruí e no campo da termoeletricidade, como menor expressividade, as usinas nucleares, como Angra 1, que iniciou sua operação em 1984.

Os estudos e planejamento realizado apontam para a necessidade de se construir os empreendimentos possíveis, expandir os sistemas interligados, bem na direção de uma interconexão regional de eletricidade. Todos esses são objetivos que começaram a fazer parte da agenda de planejamento, desde o Canambra. Contudo, ainda nesse momento, tinha-se uma operação regionalizada dos sistemas elétricos, apesar de ter avançado na questão que trata da análise de projetos inventariados.

É a partir da elaboração do Plano 95 que o planejamento se consolida, destacando a importância de se estudar e determinar um planejamento nacional. Isso se deve a decisão de se construir a usina hidrelétrica de Itaipu, o que vai exigir a operação de um sistema interligado e hidrotérmico.

Sistema esse que vai permitir que a energia gerada possa ser distribuída entre as regiões que compõem o referido sistema, existindo também o chamado sistemas isolados. Entretanto, nesse último caso, o abastecimento elétrico se fará em sua maioria por meio de usinas térmicas movidas principalmente a óleo diesel. 
A partir daqui tem-se a elaboração de um planejamento mais amplo, permitindo operar sistemas interligados e, já na década de 1980, o marco da implantação desse processo de planejamento é a criação do GCPS, cujo objetivo foi o de permitir a elaboração de planejamento de curto prazo e de planos nacionais e decenais de energia elétrica.

Sob sua responsabilidade foram elaborados vários desses planos e em cada um deles é possível perceber a dimensão que o planejamento adquire, sendo notório aspectos importantes como estimativas de déficits de energia, por meio de critérios probabilísticos, elaboração e atualização de estudos sobre o mercado de energia elétrica, a capacidade industrial do setor, determinação de projetos hidroelétricos possíveis de serem construídos, expansão térmica, movida a base de nuclear e carvão mineral, PCHs, planos de transmissão e distribuição de energia elétrica, etc.

Todos eles tinham como pré-requisitos a dimensão continental do país, os riscos hidrológicos e sua afluência e a capacidade de vazão das usinas hidrelétricas. Por outro lado, buscava-se inserir na elaboração dos estudos e do planejamento setorial, o comportamento macroeconômico, do mercado de energia elétrica, do crescimento populacional.

Enfim, esses estudos representam verdadeiros instrumentos de análise do setor elétrico do país, os quais sinalizam a expansão do sistema em bases fundamentadas nas informações colhidas por técnicos especializados. Por essa via, o Estado, suas empresas públicas e o setor de energia elétrica confluem para uma dada convergência, a de que o desenvolvimento econômico do país precisa ter, sob o prisma da tomada de decisões estratégicas, a expansão dos sistemas elétricos como sendo uma base que cimenta todos os projetos e investimentos em curso.

\section{REFERÊNCIAS}

AGÊNCIA NACIONAL DE ENERGIA ELÉTRICA (ANEEL). Energia Assegurada. Brasília: ANEEL, 2005.

ALMEIDA, P. R. A experiência brasileira em planejamento econômico: uma síntese histórica. In: GIACOMONI, J.; PAGNUSSAT, J. L. (orgs.). Planejamento e orçamento governamental. Vol. 1. Brasília: Enap, 2006. 
BAJAY, S. V. Uma revisão crítica do atual planejamento da expansão do setor elétrico brasileiro. In: Revista Brasileira de Energia. Vol. 9, nำ 1, 2002.

BENJAMIN, C. Gênese, Dinâmica e Sentido da Crise Energética Brasileira. Revista Caros Amigos. Ano V (51), junho de 2001.

CACHAPUZ, P. B. B. O planejamento da expansão do setor de energia elétrica: a atuação da Eletrobrás e do Grupo Coordenador do Planejamento dos Sistemas Elétricos (GCPS). Rio de Janeiro: Centro da Memória da Eletricidade no Brasil, 2002. (Coord.). Panorama do setor de energia elétrica do Brasil. Rio de Janeiro: Centro da Memória da Eletricidade no Brasil, 2006.

DIAS, R. F. (Coord.). Panorama do setor de energia elétrica no Brasil. Rio de Janeiro: Centro da Memória da Eletricidade no Brasil, 1988.

ECCARD, F. P. A importância da Eletrobrás para o desenvolvimento do setor elétrico brasileiro. In: Monografias Premiadas: Eletrobrás 50 anos. Rio de Janeiro: Centro Internacional Celso Furtado de Políticas para o Desenvolvimento: Eletrobrás, 2012.

EMPRESA DE PESQUISA ENERGÉTICA (EPE). Balanço Energético Nacional 2012: Ano base 2011. Rio de Janeiro: EPE, 2012.

EPE, 2013 (Relatório Síntese)

Balanço Energético Nacional 2013: ano base 2012. Rio de Janeiro:

. Balanço Nacional de Energia 2013 (Ano base 2012). Empresa de

Pesquisa Energética. Rio de Janeiro: EPE, 2013.

GOLDENBERG, J.; PRADO, L. T. S. Reforma e crise do setor elétrico no período FHC. In: USP: Tempo Social, nov., 2003.

GONÇALVES, Jr. D. Reestruturação do setor elétrico brasileiro: estratégia de retomada da taxa de acumulação de capital? São Paulo: Programa Interunidades de Pós-Graduação em Energia, Universidade de São Paulo (USP), 2002 (Tese de Doutorado).

LEITE, A. D. A Energia do Brasil. 2. ed. ver. E atual. Rio de Janeiro: Elsevier, 2007.

LIMA, J. L. Políticas de governo e desenvolvimento do setor de energia elétrica: do Código de Águas à crise dos anos 80 (1934-1984). Rio de Janeiro: Memória da Eletricidade, 1995. 
MEMÓRIA DA ELETRICIDADE. Linha do tempo. Disponível em:

http://www.memoriadaeletricidade.com.br. Acesso em: jul. 2013.

MEMÓRIAS DO DESENVOLVIMENTO. Relatório da Comissão Mista Brasil-Estados Unidos. In: Rio de Janeiro: Centro Internacional Celso Furtado de Políticas Para o Desenvolvimento, Ano II, n. 2, Jun. 2008.

MINISTÉRIO DAS MINAS E ENERGIA (MME); CENTRAIS ELÉTRICAS BRASILEIRAS S.A. (ELETROBRÁS). Plano 2010. Rio de Janeiro: MME/ELETROBRÁS, 1987.

MINISTÉRIO DAS MINAS E ENERGIA (MME). Publicações e Indicadores. Balanço Energético Nacional. Disponível em: www.mme.gov.br. Acesso em: out. 2013.

INSTITUTO DE PESQUISA ECONÔMICA APLICADA (IPEA). IPEADATA: Banco de Dados do Instituto de Pesquisa em Economia Aplicada. Macroeconômico. 2013. Disponível em: http://www.ipeadata.gov.br/. Acesso em 24/06/2014.

PINTO JUNIOR, H. Q. [Org.]; Economia da Energia. Rio de Janeiro: Elsevier, 2007.

REZENDE, F. Planejamento no Brasil: auge, declínio e caminhos para a reconstrução. Comissão Econômica para a América Latina e Caribe (Cepal), junho de 2009.

Recebido em: fevereiro de 2018

Aceito em: janeiro de 2019 